Research Article

\title{
Exogenous Hydrogen Sulfide Regulates the Growth of Human Thyroid Carcinoma Cells
}

\author{
Dongdong Wu $\mathbb{D}^{1,{ }^{1,2}}$ Jianmei Li, ${ }^{1,2}$ Qianqian Zhang, ${ }^{1,2}$ Wenke Tian, ${ }^{1,2}$ Peiyu Zhong, ${ }^{1,2}$ \\ Zhengguo Liu, ${ }^{1,2}$ Huijuan Wang, ${ }^{1,2}$ Honggang Wang, ${ }^{1,2}$ Ailing Ji $\odot$, ${ }^{1,2}$ and Yanzhang Li $\mathbb{D}^{1,2}$ \\ ${ }^{1}$ School of Basic Medical Sciences, Henan University, Kaifeng, Henan 475004, China \\ ${ }^{2}$ Henan International Joint Laboratory for Nuclear Protein Regulation, Henan University, Kaifeng, Henan 475004, China \\ Correspondence should be addressed to Ailing Ji; ailingji@163.com and Yanzhang Li; yanzhang206@163.com
}

Received 1 November 2018; Revised 24 February 2019; Accepted 23 April 2019; Published 16 May 2019

Academic Editor: Daniela Giustarini

Copyright (C) 2019 Dongdong Wu et al. This is an open access article distributed under the Creative Commons Attribution License, which permits unrestricted use, distribution, and reproduction in any medium, provided the original work is properly cited.

\begin{abstract}
Hydrogen sulfide $\left(\mathrm{H}_{2} \mathrm{~S}\right)$ is involved in the development and progression of many types of cancer. However, the effect and mechanism of $\mathrm{H}_{2} \mathrm{~S}$ on the growth of human thyroid carcinoma cells remain unknown. In the present study, we found that the proliferation, viability, migration, and invasion of human thyroid carcinoma cells were enhanced by $25-50 \mu \mathrm{M} \mathrm{NaHS}$ (an $\mathrm{H}_{2} \mathrm{~S}$ donor) and inhibited by $200 \mu \mathrm{M}$ NaHS. However, $\mathrm{H}_{2} \mathrm{~S}$ showed no obvious effects on the proliferation, viability, and migration of human normal thyroid cells. Administration of $50 \mu \mathrm{M}$ NaHS increased the expression levels of CBS, SQR, and TST, while $200 \mu \mathrm{M}$ NaHS showed reverse effects in human thyroid carcinoma cells. After treatment with 25-50 $\mu \mathrm{M}$ NaHS, the ROS levels were decreased and the protein levels of p-PI3K, p-AKT, p-mTOR, H-RAS, p-RAF, p-MEK1/2, and p-ERK1/2 were increased, whereas $200 \mu \mathrm{M}$ NaHS exerted opposite effects in human thyroid carcinoma cells. Furthermore, $1.4-2.8 \mathrm{mg} / \mathrm{kg} / \mathrm{day} \mathrm{NaHS}$ promoted the tumor growth and blood vessel formation in human thyroid carcinoma xenograft tumors, while $11.2 \mathrm{mg} / \mathrm{kg} / \mathrm{day}$ $\mathrm{NaHS}$ inhibited the tumor growth and angiogenesis. In conclusion, our results demonstrate that exogenous $\mathrm{H}_{2} \mathrm{~S}$ regulates the growth of human thyroid carcinoma cells through ROS/PI3K/Akt/mTOR and RAS/RAF/MEK/ERK signaling pathways. Novel $\mathrm{H}_{2} \mathrm{~S}$-releasing donors/drugs can be designed and applied for the treatment of thyroid cancer.
\end{abstract}

\section{Introduction}

Hydrogen sulfide $\left(\mathrm{H}_{2} \mathrm{~S}\right)$ is the third member of the gasotransmitter family along with nitric oxide and carbon monoxide [1-3]. $\mathrm{H}_{2} \mathrm{~S}$ can be endogenously produced from L-cysteine (L-Cys) and homocysteine in mammalian tissues mainly by two pyridoxal-5' ${ }^{\prime}$-phosphate- (PLP-) dependent enzymes, cystathionine $\beta$-synthase (CBS) and cystathionine $\gamma$-lyase (CSE). CBS and CSE are predominantly cytosolic enzymes [4-6]. 3-Mercaptopyruvate sulfurtransferase (3-MST) is a PLP-independent enzyme that acts in combination with cysteine aminotransferase (CAT) to produce $\mathrm{H}_{2} \mathrm{~S}$ from L-Cys in the presence of $\alpha$-ketoglutarate. 3-MST and CAT are located in the cytosol and mitochondria [6-8]. In addition, D-amino acid oxidase metabolizes $\mathrm{D}$-cysteine to an achiral $\alpha$-ketoacid, 3-mercaptopyruvate, which can be further metabolized to $\mathrm{H}_{2} \mathrm{~S}$ by 3-MST in both the brain and the kidney [9]. $\mathrm{H}_{2} \mathrm{~S}$ can be immediately released or stored in the forms of bound sulfane sulfur and acid-labile sulfur in the cells [10-13].

There is increasing evidence that $\mathrm{H}_{2} \mathrm{~S}$ plays important roles in a number of physiological conditions, including angiogenesis [14], vascular relaxation [15], neuronal activity [16], energy production [17], and glucose regulation [18]. However, abnormal $\mathrm{H}_{2} \mathrm{~S}$ metabolism is associated with many diseases, such as atherosclerosis [19], diabetes [20], asthma [21], hypertension [22], and neurodegenerative diseases [23]. Thyroid cancer is the most common endocrine-related cancer with a rapid worldwide rise in incidence in the past few decades [24]. The prognosis of thyroid cancer is correlated with the progression of localized primary tumors to advanced stages, which ultimately metastasizes to multiple organs [25]. It has been shown that $\mathrm{H}_{2} \mathrm{~S}$ is involved in the development and progression of many different types of cancer [5, 26-28]. However, the effect and mechanism of 
Nthy-ori3-1
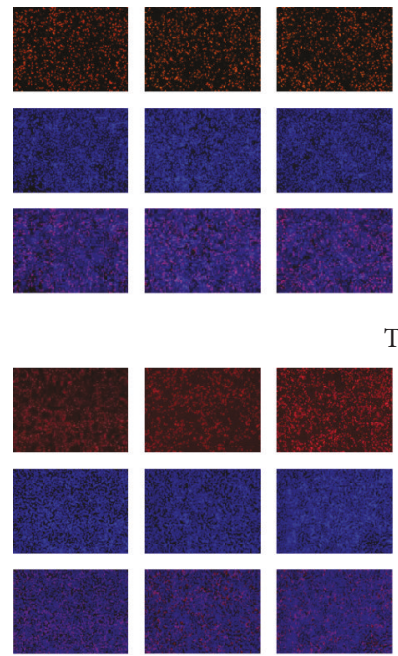

Control

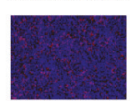

10
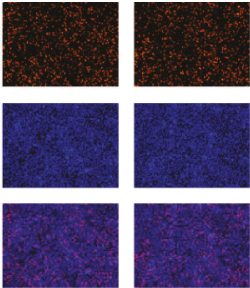

TT
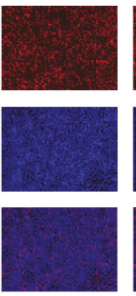

25
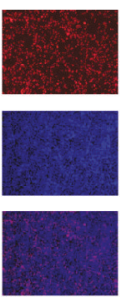

50
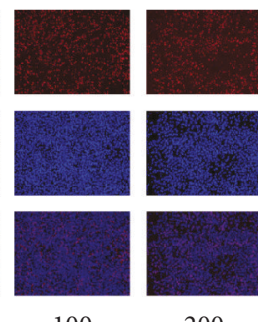

100

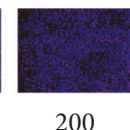

NaHS $(\mu \mathrm{M})$

TPC-1
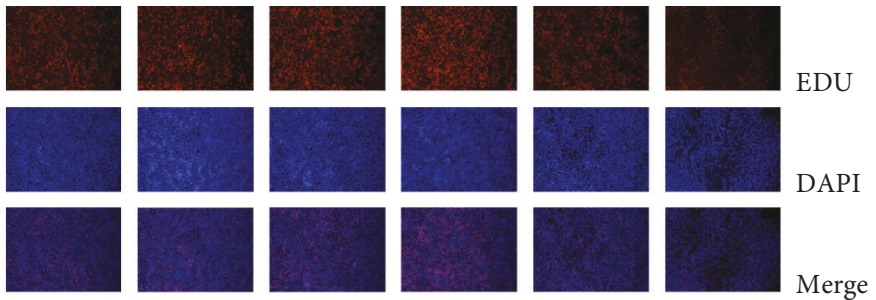

ARO
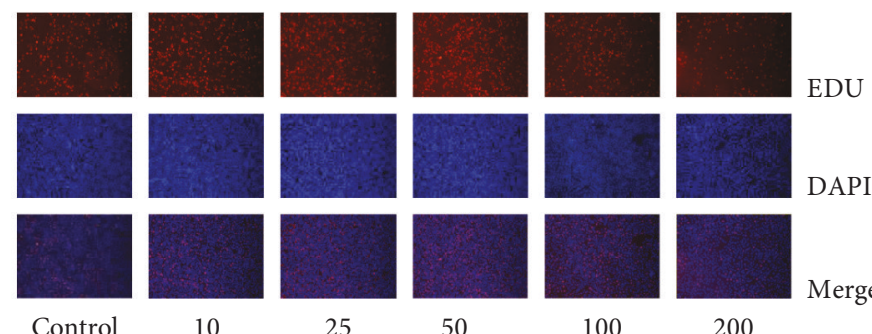

25

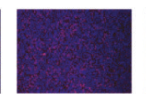

50

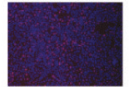

100

200

(a)
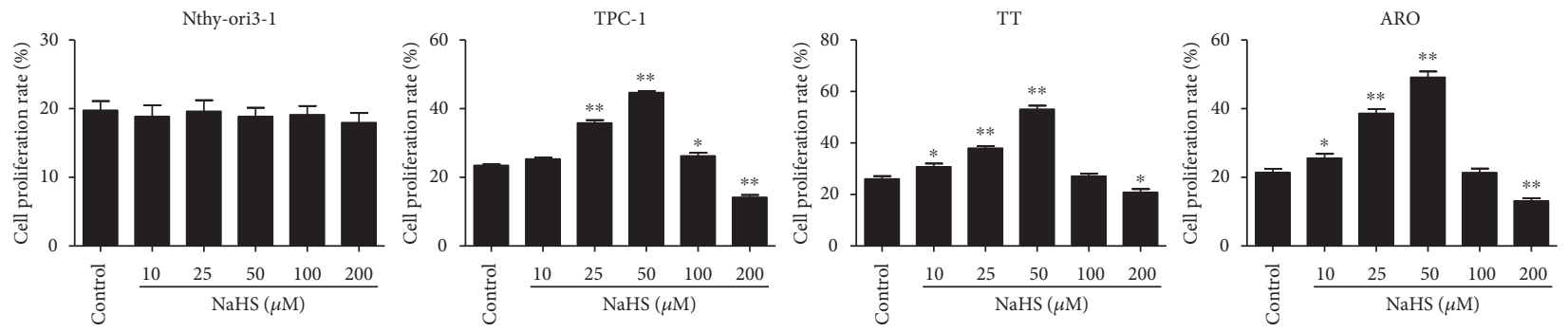

(b)
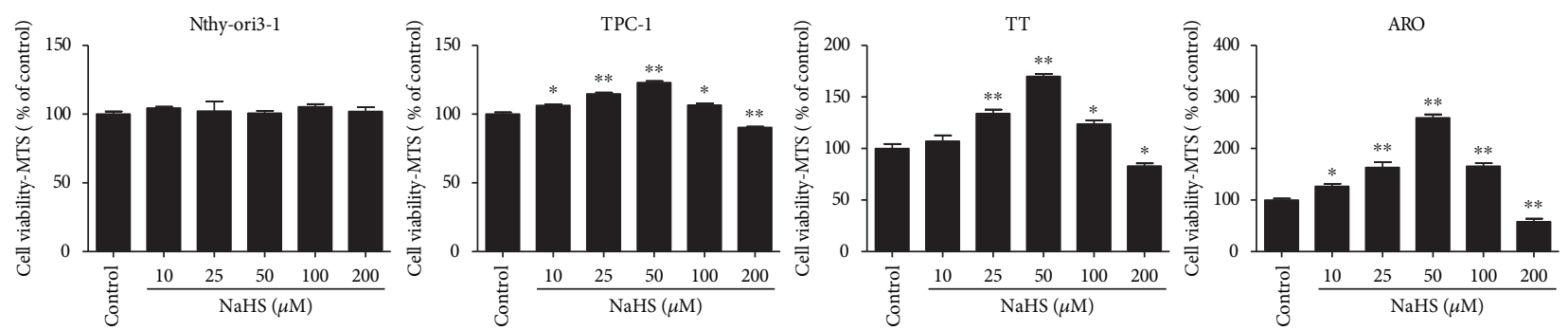

(c)
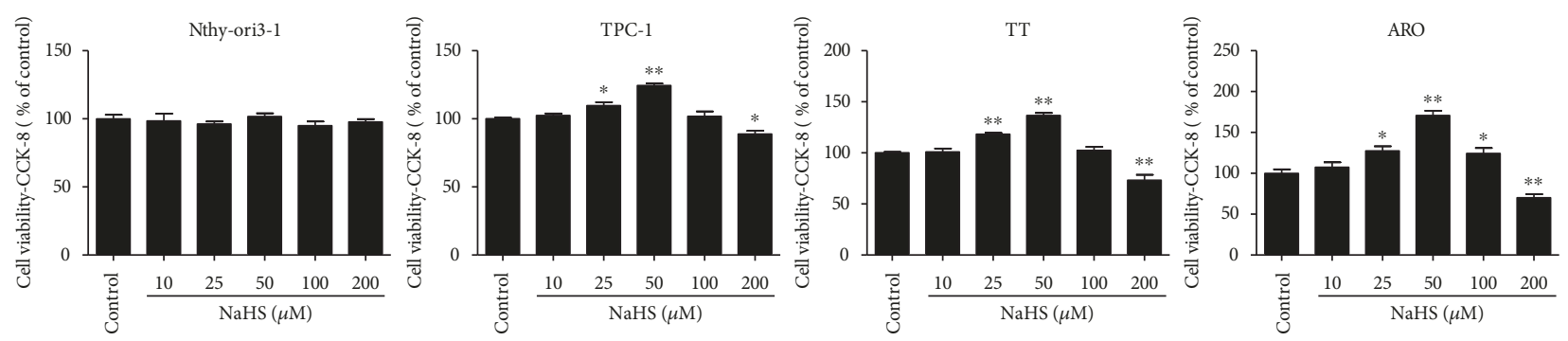

(d)

FIGURE 1: Effects of exogenous $\mathrm{H}_{2} \mathrm{~S}$ on the proliferation and viability of human thyroid carcinoma cells and human normal thyroid cells. (a) DNA replication activities of Nthy-ori3-1, TPC-1, TT, and ARO in each group were examined by EdU assay; original magnification $\times 200$. (b) The proliferation rate of each group was analyzed $(n=6)$. (c) The percentages of viable cells were determined using the MTS assay, and the cell viability of every cell line without NaHS treatment was normalized as $100 \%$ and considered to be the control group $(n=3)$. (d) The percentages of viable cells were determined using the CCK-8 assay, and the cell viability of every cell line without NaHS treatment was normalized as $100 \%$ and considered to be the control group $(n=3) .{ }^{*} P<0.05,{ }^{* *} P<0.01$ compared with the control group. 

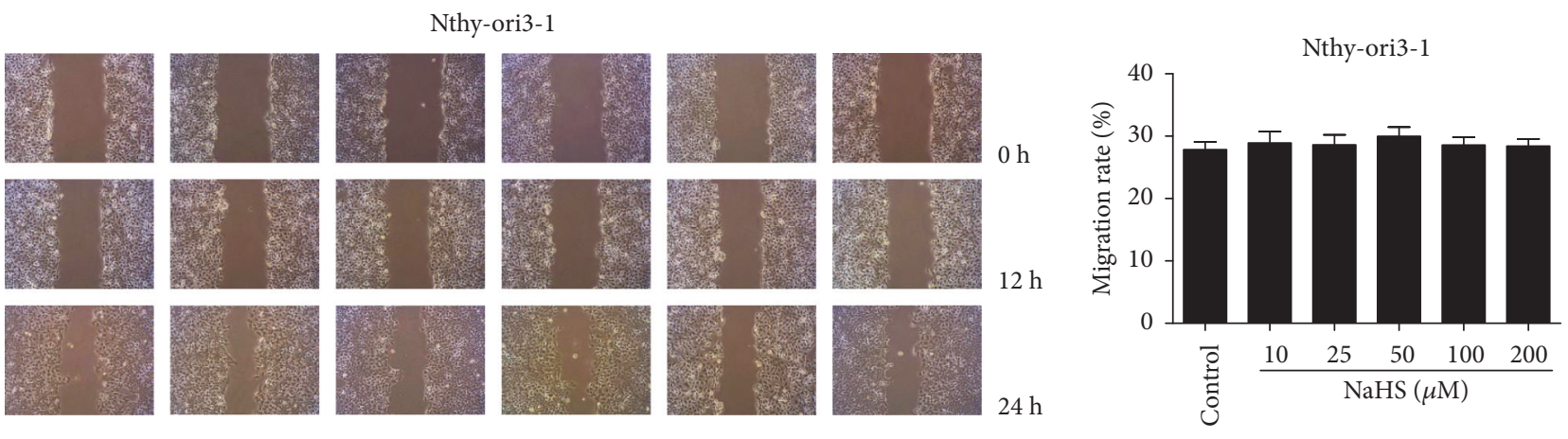

(a)

TPC-1
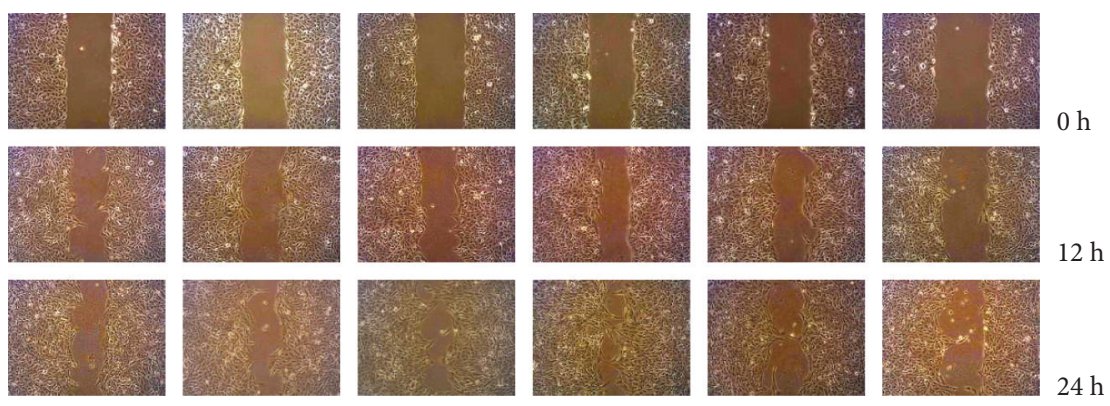

(b)

TT
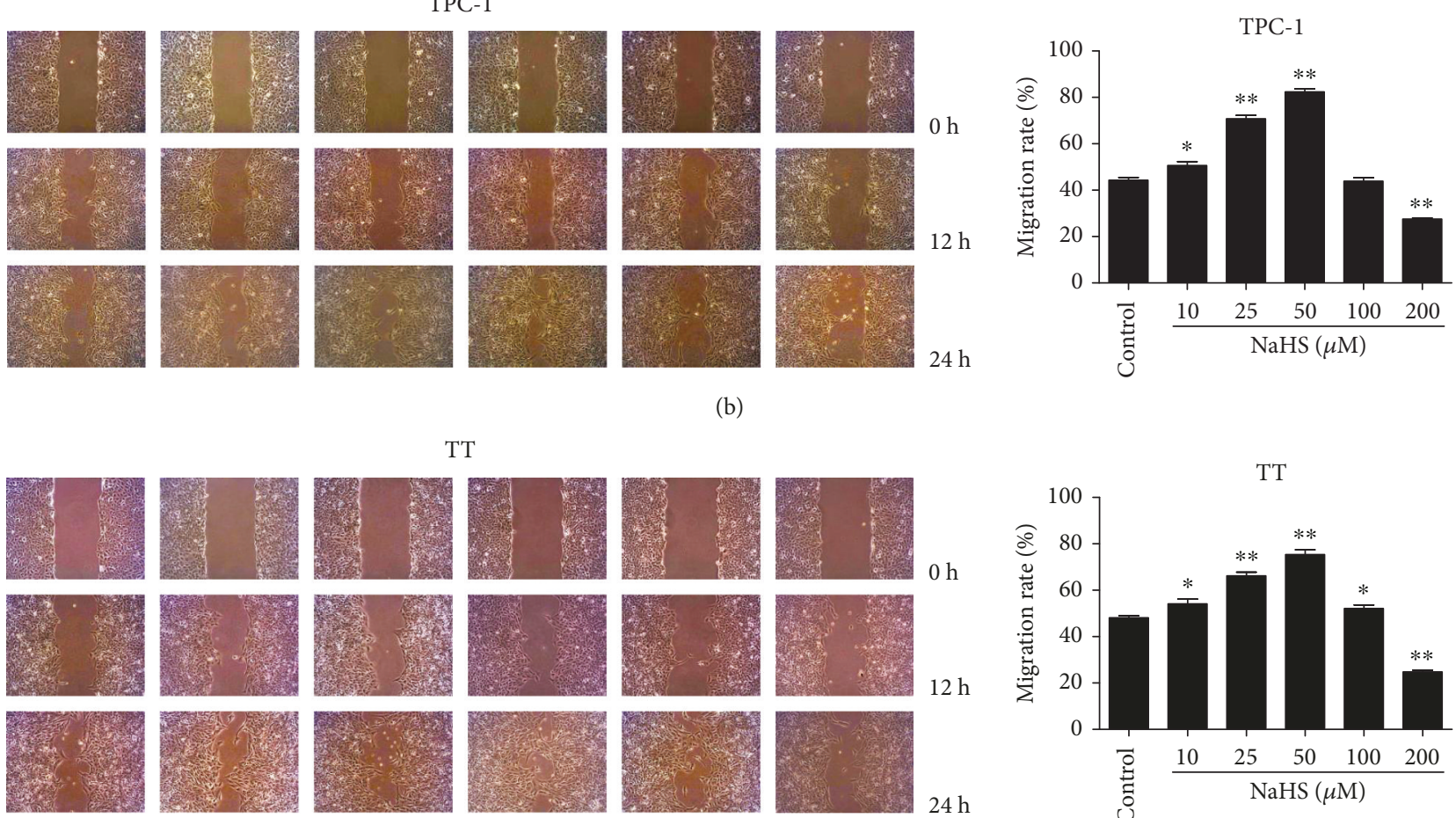

(c)

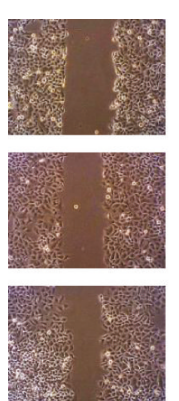

Control

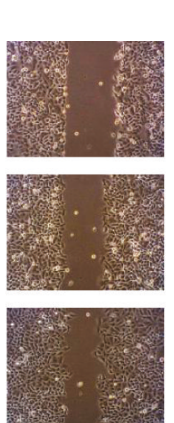

10

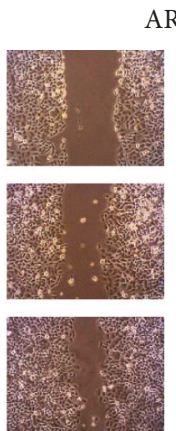

25

ARO

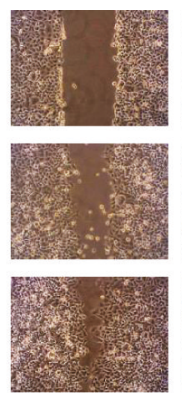

50

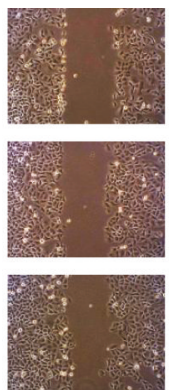

100

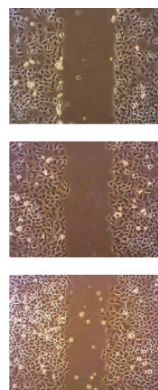

200

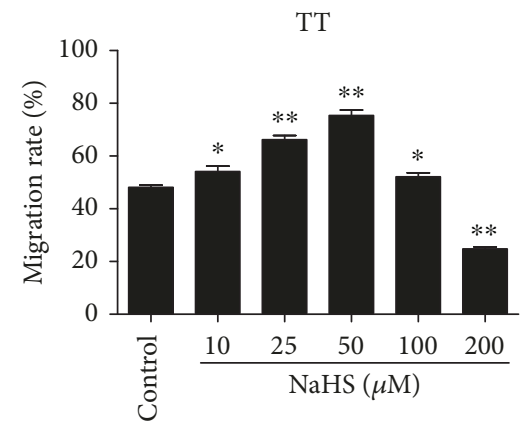

NaHS $(\mu \mathrm{M})$

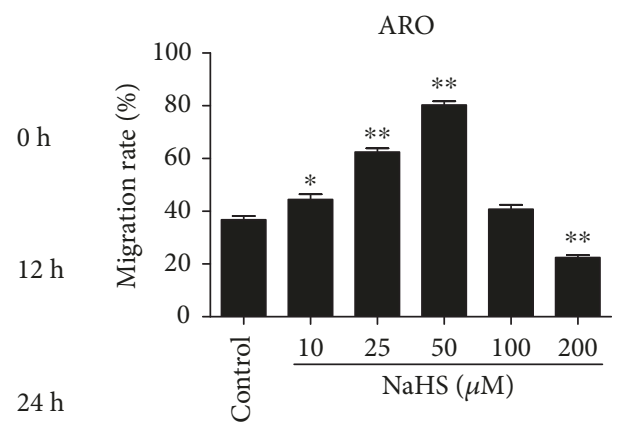

(d)

Figure 2: Effects of exogenous $\mathrm{H}_{2} \mathrm{~S}$ on the migration of human thyroid carcinoma cells and human normal thyroid cells. (a-d) Cell migration was measured by wound healing assay (original magnification $\times 100$ ), and the migration rates of Nthy-ori3-1, TPC-1, TT, and ARO cells were calculated after treatment for $24 \mathrm{~h}(n=6) .{ }^{*} P<0.05,{ }^{* *} P<0.01$ compared with the control group. 
TPC-1

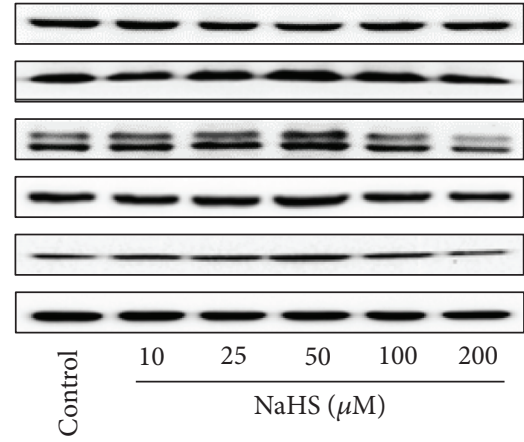

TPC-1

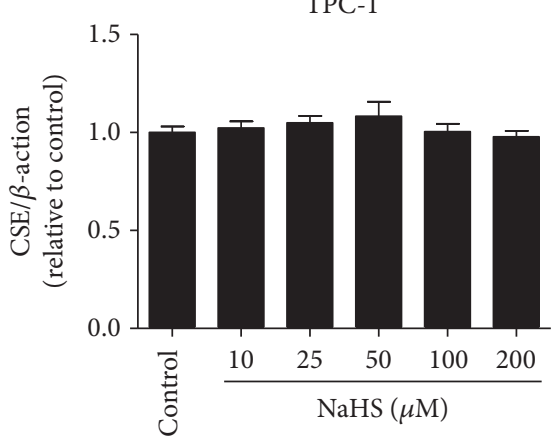

TPC-1

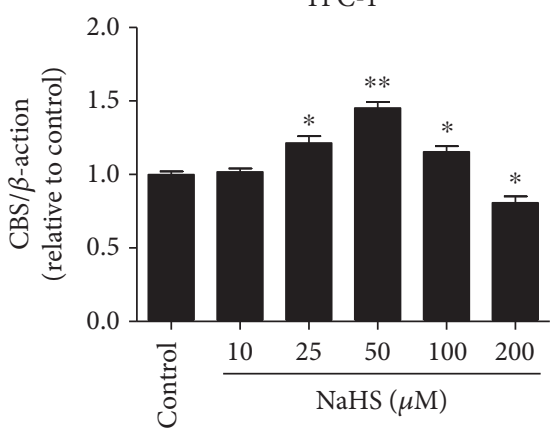

TPC-1

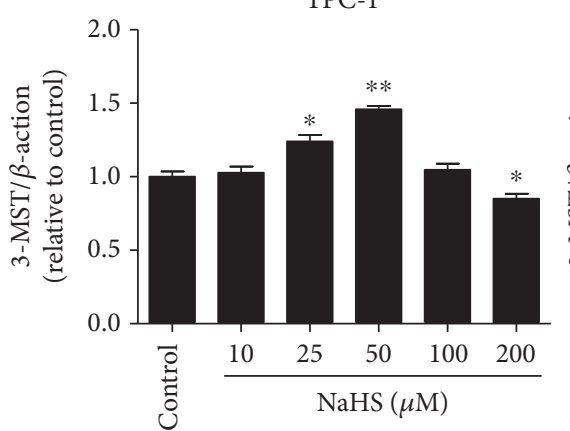

TT

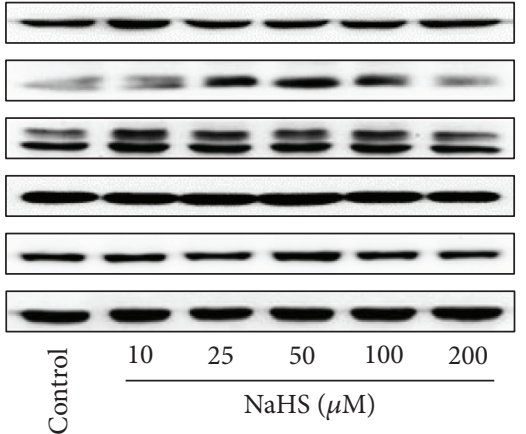

(a)
ARO

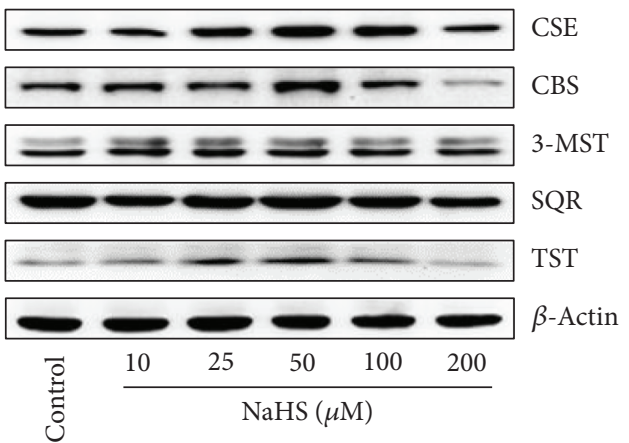

ARO

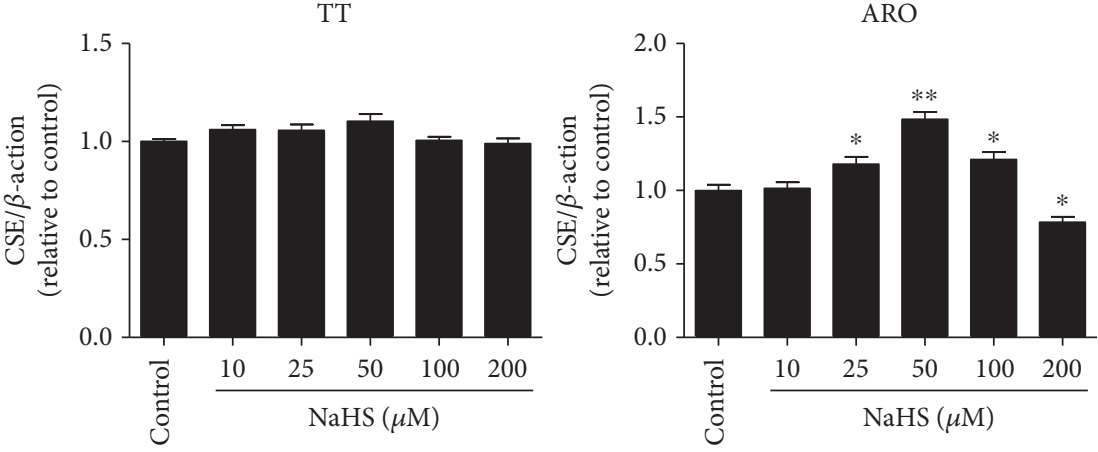

(b)

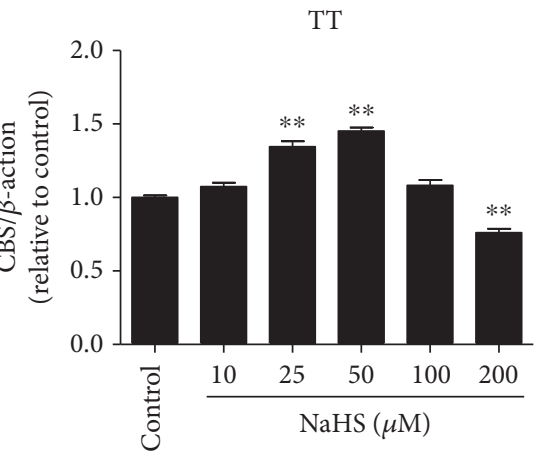

(c)
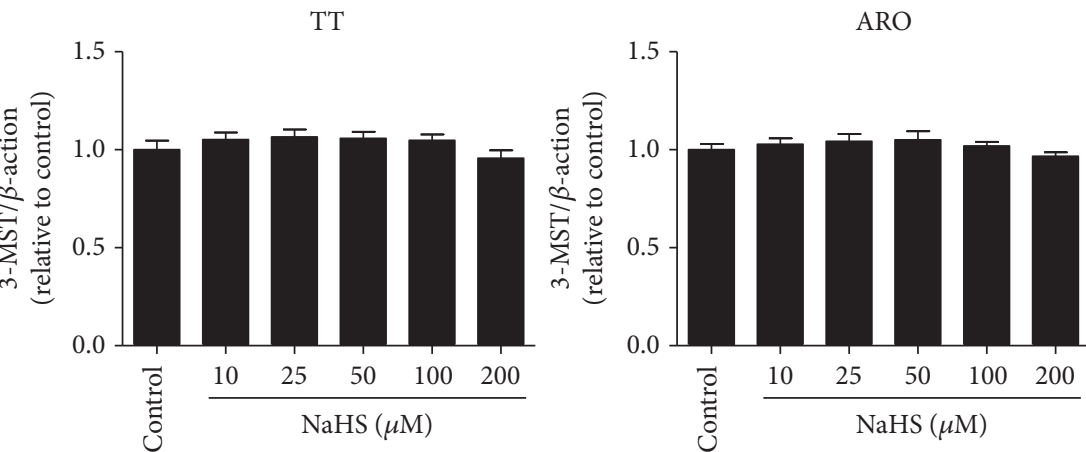

(d)

Figure 3: Continued. 

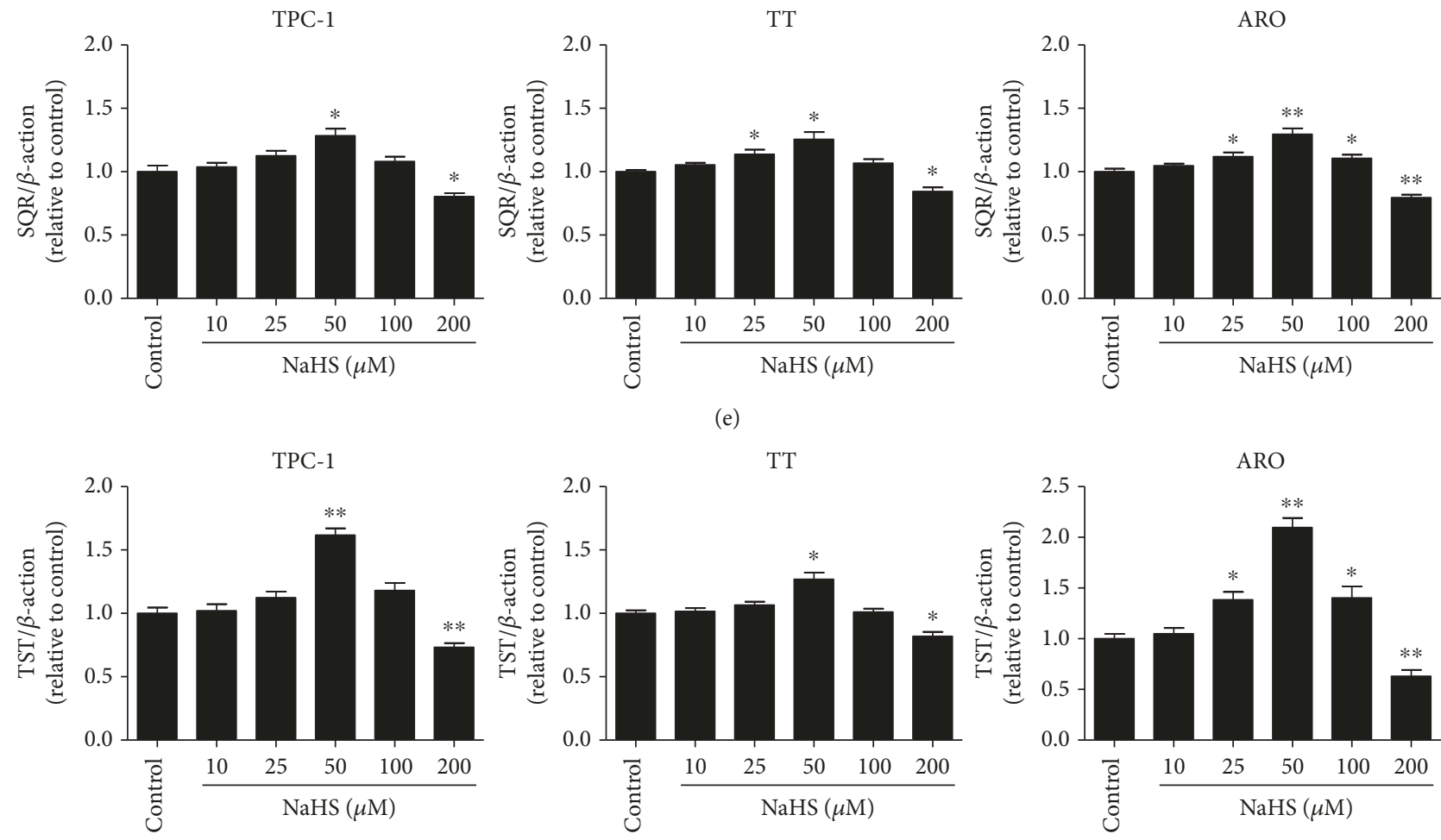

(f)

Figure 3: Effects of exogenous $\mathrm{H}_{2} \mathrm{~S}$ on the protein levels of $\mathrm{H}_{2} \mathrm{~S}$-generating enzymes and $\mathrm{H}_{2} \mathrm{~S}$-degradating enzymes in human thyroid carcinoma cells. (a) Western blotting analysis of the expressions of CSE, CBS, 3-MST, SQR, and TST in TPC-1, TT, and ARO cells. $\beta$-Actin was used as the loading control. (b-f) The intensities of the bands were quantified by densitometry analyses and normalized by the amount of $\beta$-actin $(n=3) .{ }^{*} P<0.05,{ }^{* *} P<0.01$ compared with the control group.

$\mathrm{H}_{2} \mathrm{~S}$ on the growth of human thyroid carcinoma cells remain unknown.

In this study, we investigated the effect and mechanism of $\mathrm{H}_{2} \mathrm{~S}$ on the proliferation, viability, migration, and invasion of human thyroid carcinoma cells. We further examined the effects of $\mathrm{H}_{2} \mathrm{~S}$ on tumor growth and angiogenesis in nude mice xenografted with human thyroid carcinoma.

\section{Materials and Methods}

2.1. Cell Culture. Human normal thyroid cell line Nthy-ori3-1 and human thyroid carcinoma cell lines TPC-1, TT, and ARO were obtained from CoBioer Biosciences Co. Ltd. (Nanjing, Jiangsu, China). Cells were cultured in RPMI 1640 medium supplemented with $10 \%$ fetal bovine serum, 100 units $/ \mathrm{ml}$ penicillin, and $100 \mu \mathrm{g} / \mathrm{ml}$ streptomycin. Cells were grown at $37^{\circ} \mathrm{C}$ in a humidified atmosphere of $95 \%$ air and 5\% $\mathrm{CO}_{2}$ [29]. Confluent cells were starved overnight in a serum-free RPMI 1640 medium. The cells were then treated with $10,25,50,100$, and $200 \mu \mathrm{M}$ NaHS (an $\mathrm{H}_{2} \mathrm{~S}$ donor, Sigma-Aldrich, St. Louis, MO, USA) for 24 h. The phosphate-buffered saline (PBS) group was served as a control.

2.2. 5-Ethynyl-2' -Deoxyuridine (EdU) Assay. Cell proliferation ability was detected by the Cell-Light EdU Apollo 567 In Vitro Imaging Kit (RiboBio, Guangzhou, Guangdong,
China). Cell proliferation rate $=$ (number of EdU - positive cells $) /($ total number of cells $) \times 100 \%[30]$.

2.3. MTS Assay. The cell viability was detected using the CellTiter $96 \mathrm{AQ}_{\text {ueous }}$ One Solution Cell Proliferation Assay kit (MTS; Promega, Madison, WI, USA).

2.4. Cell Counting Kit-8 (CCK-8) Assay. The CCK-8 detection kit (Beyotime Institute of Biotechnology, Shanghai, China) was used to measure cell viability.

2.5. Wound Healing Assay. Cultured cells in confluent monolayer were wounded using a sterile micropipette tip. Cell migration was observed under an Olympus CKX41 microscope and measured using the ImageJ software (National Institute for Health, Bethesda, MD, USA). The migration rate (MR) was calculated according to the formula: $\mathrm{MR}=[(A-B) / A] \times 100 \%$, where $A$ is the width at $0 \mathrm{~h}$ and $B$ is the width at $24 \mathrm{~h} \mathrm{[29].}$

2.6. Colony Formation Assay. Cells $\left(8 \times 10^{2} /\right.$ well $)$ were cultured in 6-well plates for 2 weeks at $37^{\circ} \mathrm{C}$. At room temperature, colonies were fixed with methanol for $15 \mathrm{~min}$ and subsequently stained with $0.5 \%$ crystal violet for $30 \mathrm{~min}$. The plates were scanned and the numbers of colonies were counted [31].

2.7. Soft Agar Assay. Cells $\left(1 \times 10^{4} /\right.$ well $)$ were suspended in the medium containing $0.6 \%$ agarose and overlaid onto a basal layer of $1.2 \%$ agarose in 6 -well plates. After 14 days, 


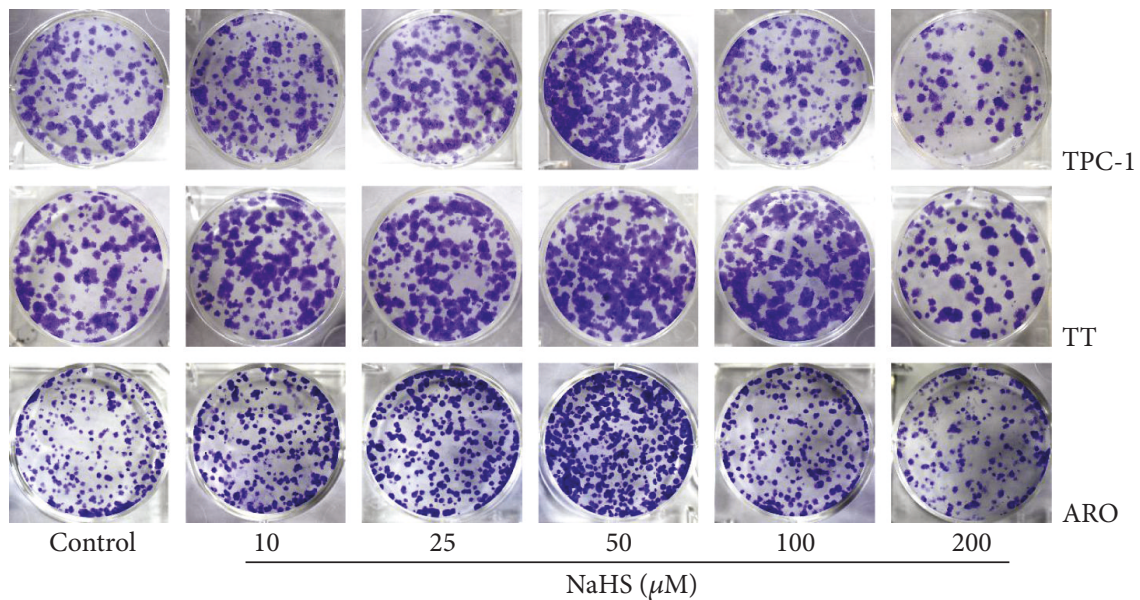

(a)
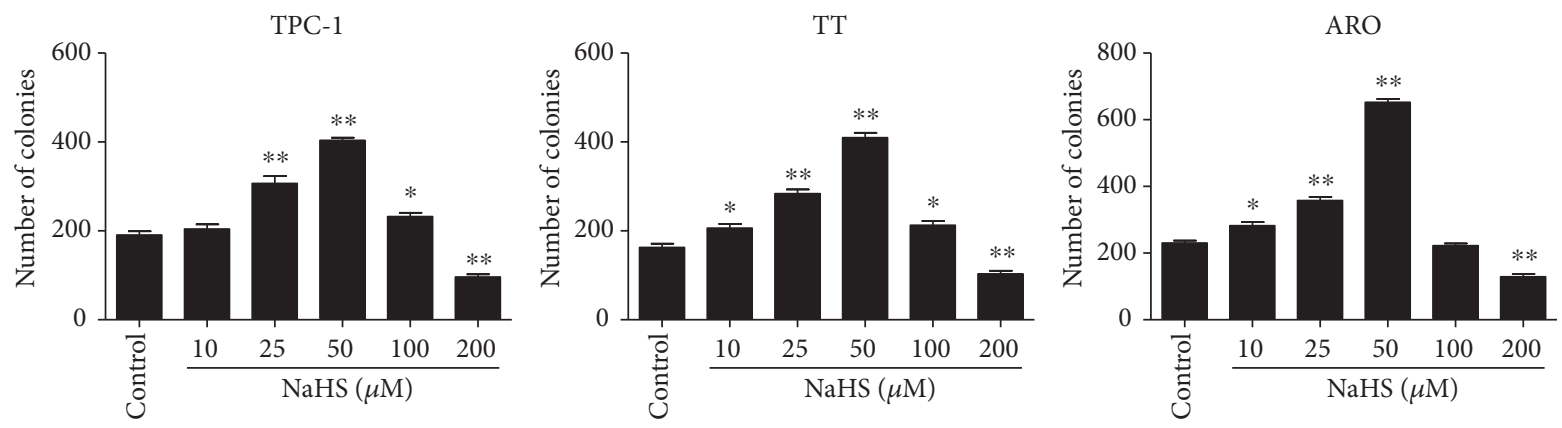

(b)
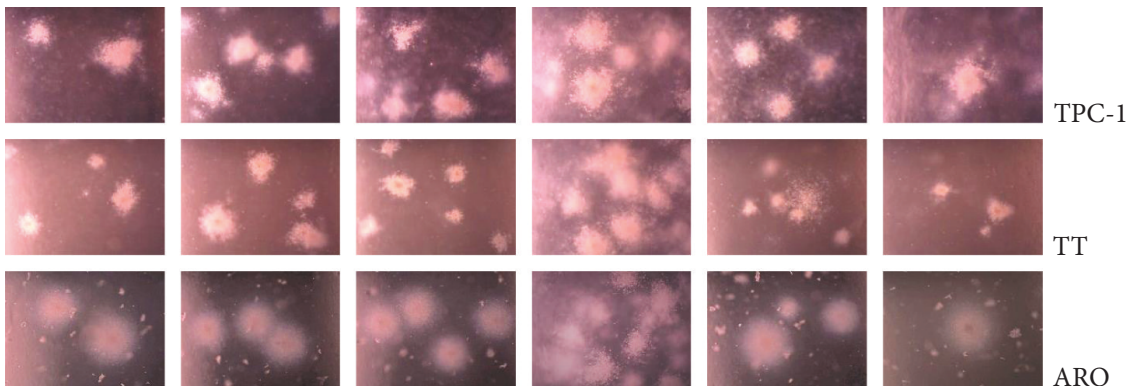

Control

10

25

NaHS $(\mu \mathrm{M})$

(c)
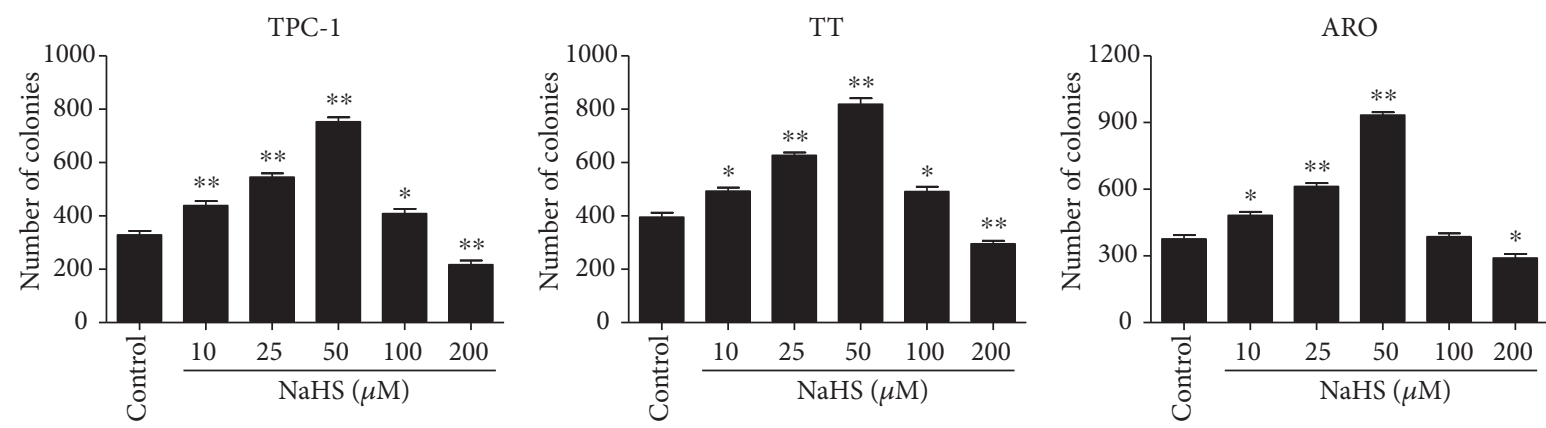

(d)

Figure 4: Effects of exogenous $\mathrm{H}_{2} \mathrm{~S}$ on the colony formation ability of human thyroid carcinoma cells. (a) The clonogenic capacity was determined in TPC-1, TT, and ARO cells. (b) The number of colonies was calculated $(n=3)$. (c) Soft agar assay was performed to examine the anchorage-independent survival of cells; original magnification $\times 100$. (d) The number of colonies was calculated $(n=3)$. ${ }^{*} P<0.05,{ }^{* *} P<0.01$ compared with the control group. 


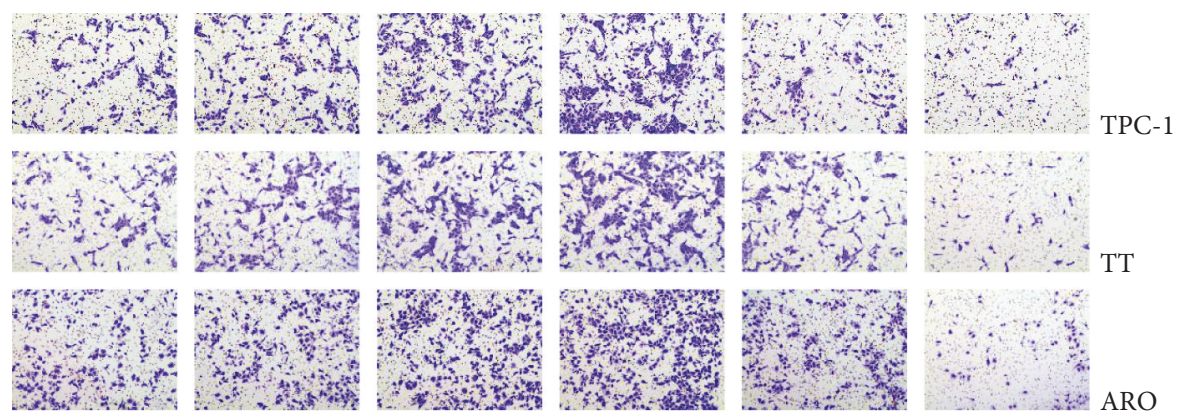

(a)

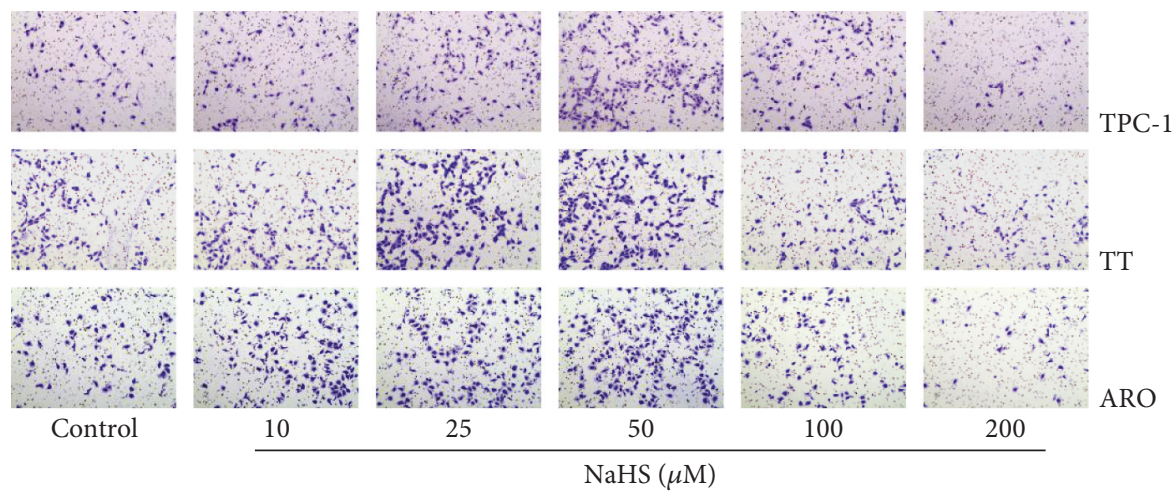

(b)
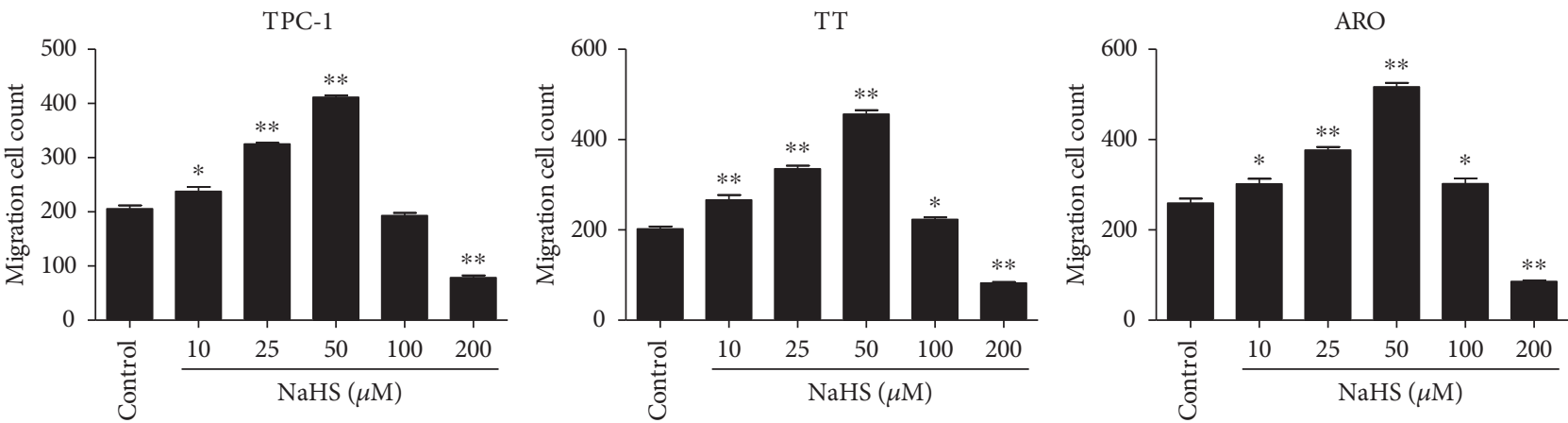

(c)
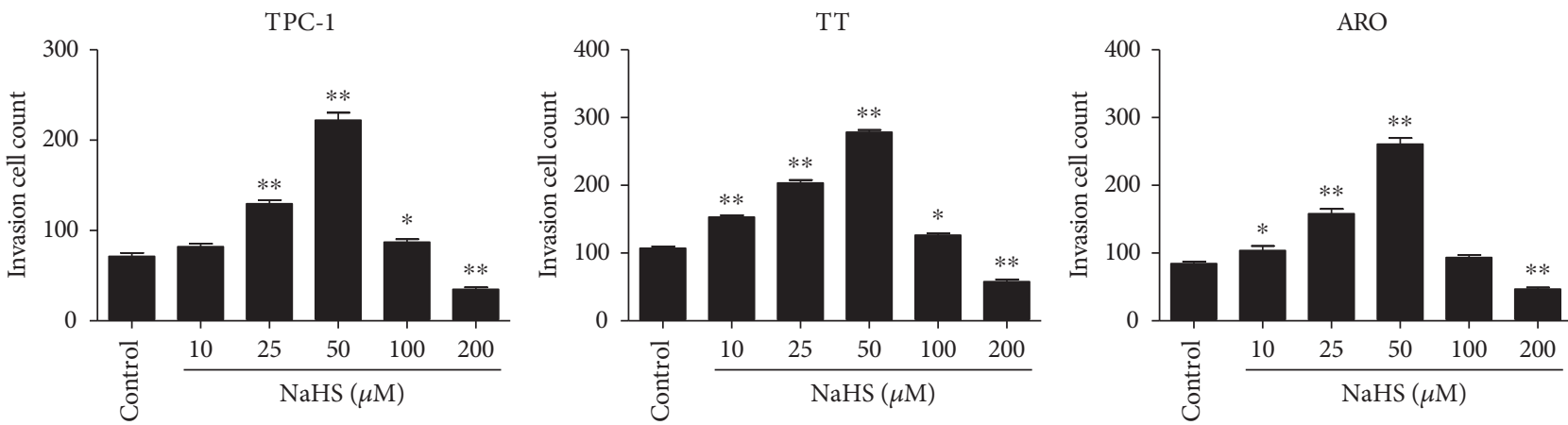

(d)

Figure 5: Effects of exogenous $\mathrm{H}_{2} \mathrm{~S}$ on the migration and invasion of human thyroid carcinoma cells. (a) Transwell assay was performed to assess the migration of TPC-1, TT, and ARO cells; original magnification $\times 200$. (b) Transwell assay was performed to assess the invasion of TPC-1, TT, and ARO cells; original magnification $\times 200$. (c) The number of the migrated cells was calculated $(n=6)$. (d) The number of the invasive cells was calculated $(n=6) .{ }^{*} P<0.05,{ }^{* *} P<0.01$ compared with the control group. 

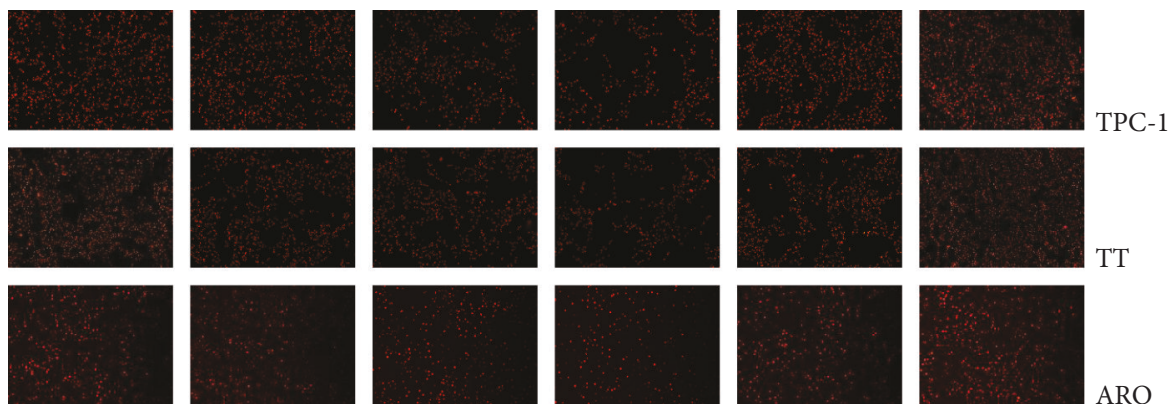

Control

$$
25
$$

100

200

(a)

TPC-1

TT

ARO
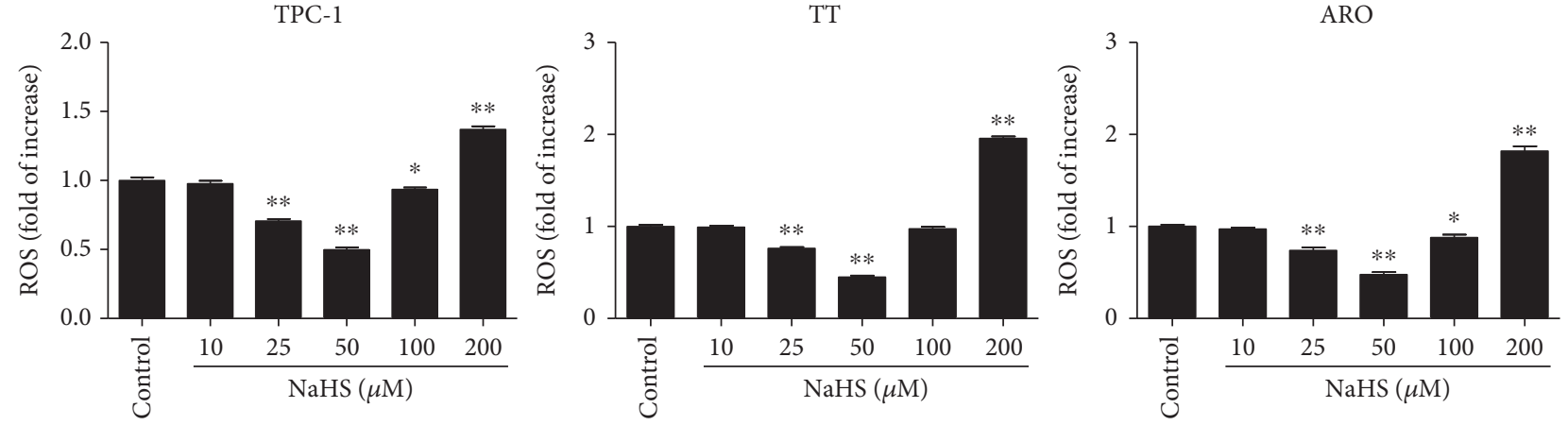

(b)

TPC -1

ARO

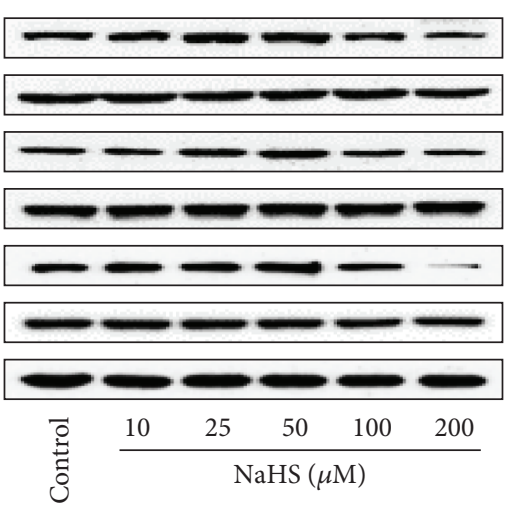

TPC-1
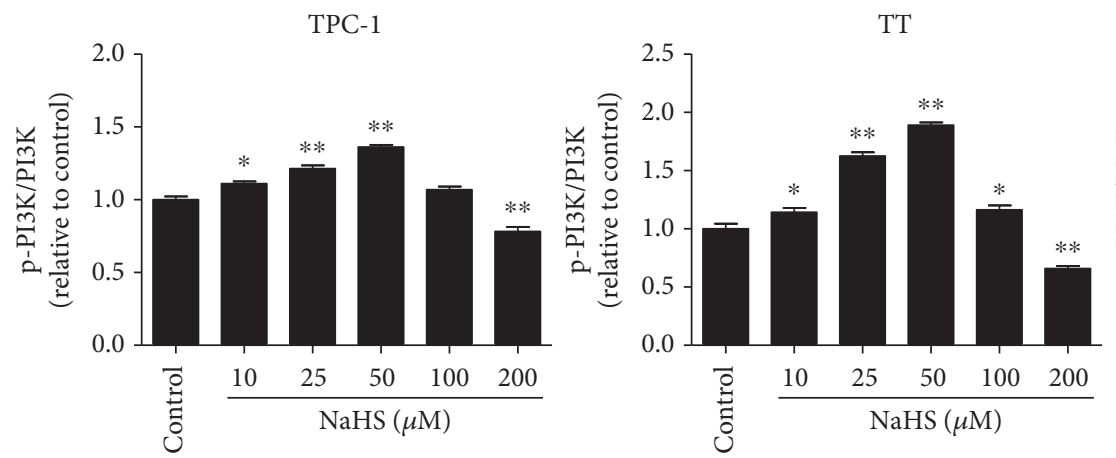

(d)

Figure 6: Continued.

(c)

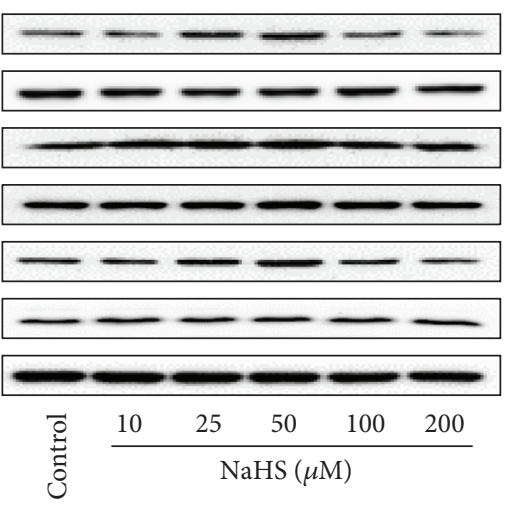

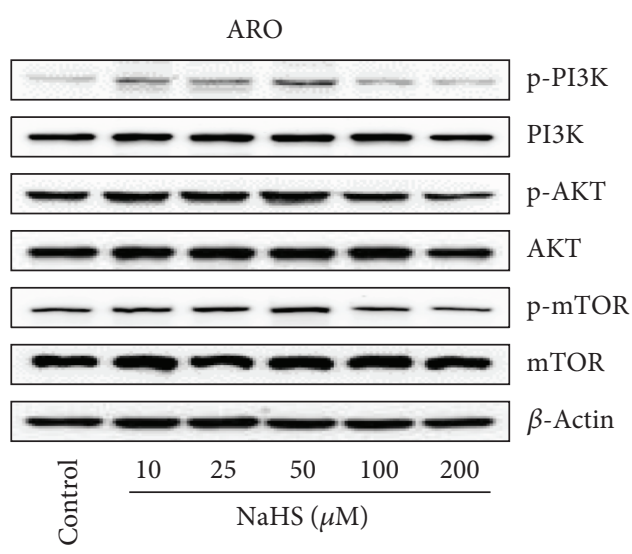

$\longrightarrow-20 \mathrm{AKT}$

ARO

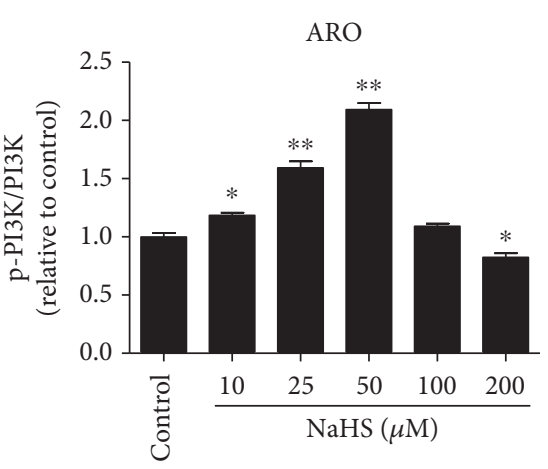

站 $\frac{10 \quad 25 \quad 50 \quad 100 \quad 200}{\mathrm{NaHS}(\mu \mathrm{M})}$ 

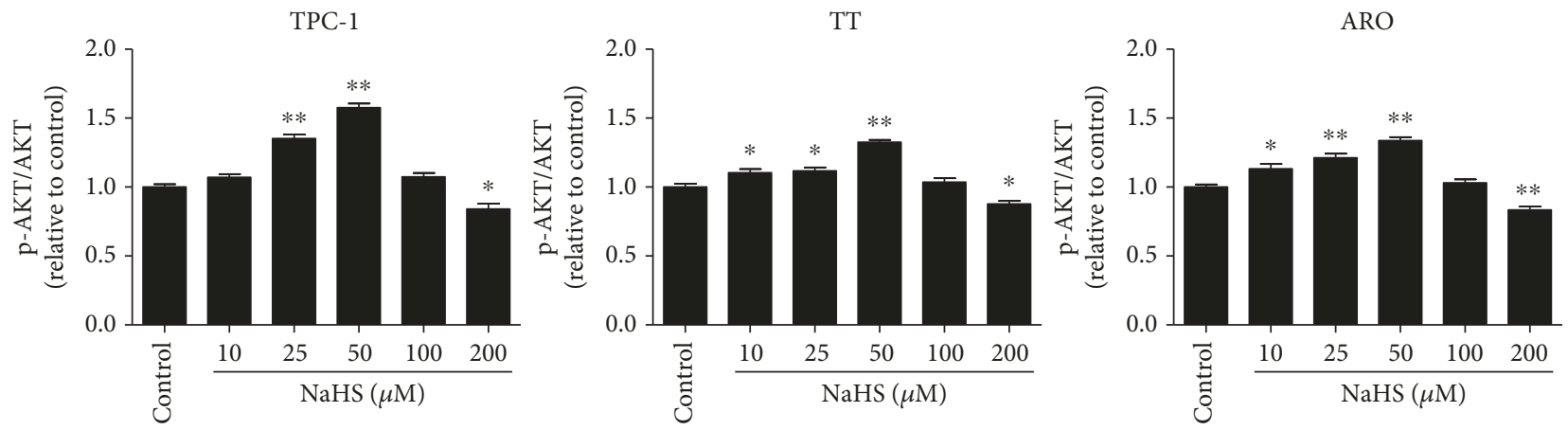

(e)
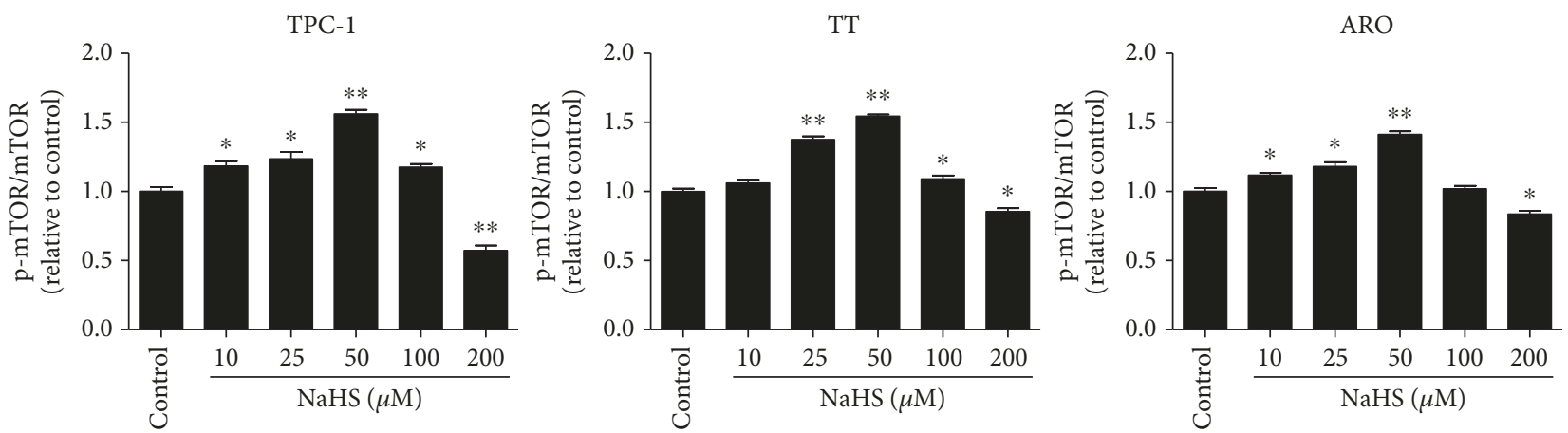

(f)

FIGURE 6: Effects of exogenous $\mathrm{H}_{2} \mathrm{~S}$ on the ROS/PI3K/Akt/mTOR signaling pathway in human thyroid carcinoma cells. (a) The intracellular ROS production was detected using the fluorescent probes DHE (shown in red; original magnification, $\times 100$ ). (b) The intracellular ROS production was measured $(n=6)$. (c) Western blotting analysis of the expressions of PI3K, p-PI3K, AKT, p-AKT, mTOR, and p-mTOR in TPC-1, TT, and ARO cells. $\beta$-Actin was used as the loading control. (d-f) The intensities of the bands were quantified by densitometry analyses and normalized by the amount of PI3K, AKT, and mTOR, respectively $(n=3) .{ }^{*} P<0.05$, ${ }^{* *} P<0.01$ compared with the control group.

colonies were observed under an Olympus CKX41 microscope and the numbers of colonies were counted [31].

2.8. Migration and Invasion Assays. Migration and invasion assays were performed as previously described [29]. The numbers of stained cells were counted using a Zeiss Axioskop 2 plus microscope (Carl Zeiss, Thornwood, NY, USA).

2.9. Detection of Intracellular Reactive Oxygen Species (ROS). Intracellular ROS were detected by using a Dihydroethidium (DHE) Cellular ROS Detection Assay Kit (Vigorous Biotechnology, Beijing, China).

2.10. Western Blotting. After treatment for $24 \mathrm{~h}$, total protein was extracted from TPC-1, TT, and ARO cells. Western blotting was performed to detect the expression of target proteins. The primary antibodies, including anti- $\beta$-actin, anti-CSE, anti-CBS, anti-3-MST, antisulfide-quinone reductase (SQR), antithiosulfate sulfurtransferase (TST), antiphosphatidylinositol 3-kinase (PI3K), anti-phospho (p)-PI3K (Tyr458/Tyr199), anti-AKT, anti-p-AKT (Ser473), antimammalian target of rapamycin (mTOR), anti-p-mTOR (Ser2448), anti-H-RAS, anti-RAF, anti-p-c-RAF (Ser259), anti-MEK1/2, anti-p-MEK1/2 (Ser217/221), antiextracellular signal-regulated protein kinase $1 / 2$ (ERK1/2), anti-pERK1/2 (Thr202/Tyr204), and the horseradish peroxidase- conjugated secondary antibody were purchased from Cell Signaling Technology (CST, Danvers, MA, USA). The results were normalized to the level of $\beta$-actin. The reaction was visualized using an enhanced chemiluminescence system (Thermo Fisher Scientific, Rockford, IL, USA). The bands were semiquantified with ImageJ software.

2.11. Animal Study. Animal experiments were approved by the Committee of Medical Ethics and Welfare for Experimental Animals of Henan University School of Medicine (HUSOM-2017-189) in compliance with the Experimental Animal Regulations formulated by the National Science and Technology Commission, China. Animal studies were conducted as previously described with slight modifications [32]. Forty-eight 4-week-old male BALB/C nude mice ( $n=8$ per group) were purchased from Beijing HFK Bioscience Co. Ltd. (Certificate No. SCXK (Jing) 2014-0004, Beijing, China). TPC-1, TT, and ARO cells $\left(5 \times 10^{6}\right.$ cells in $200 \mu \mathrm{l}$ PBS) were implanted by subcutaneous injection into the right flanks of mice. Then, the mice were randomly divided into six groups ( $n=8$ per group). NaHS $(0.56,1.4$, $2.8,5.6$, and $11.2 \mathrm{mg} / \mathrm{kg} /$ day) was administered subcutaneously (near the implanted tumor) for 4 weeks. The control group was treated with PBS. Body weight and tumor volume were daily measured. Tumor volume was calculated as volume $=L \times W^{2} / 2$, where $L$ is the longest dimension and 
TPC-1

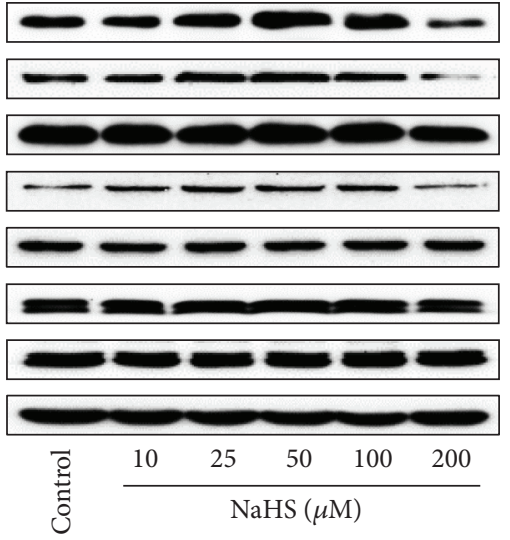

TPC-1

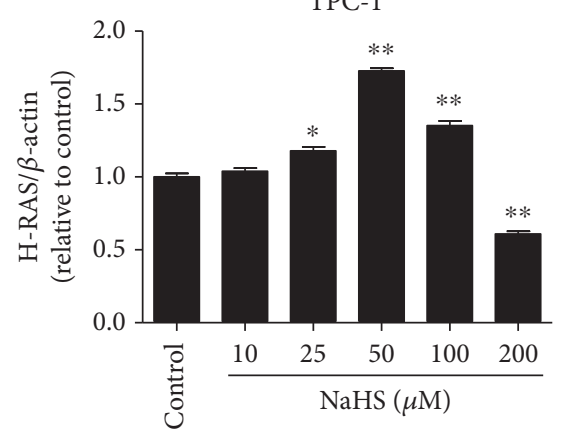

TPC-1

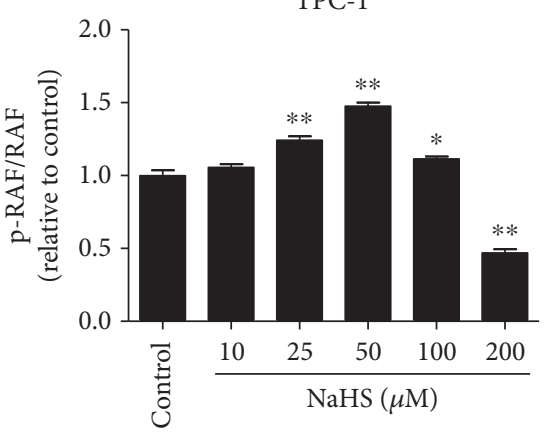

TPC-1

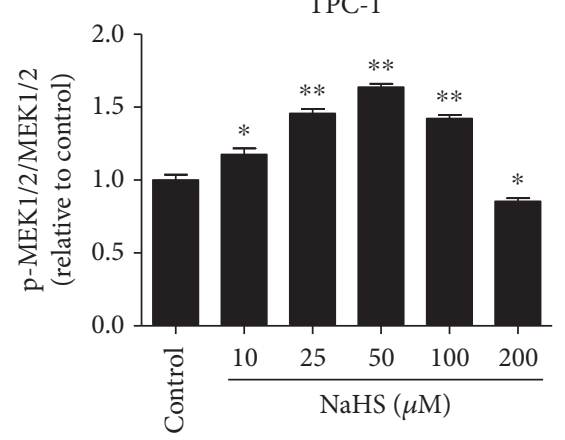

TT

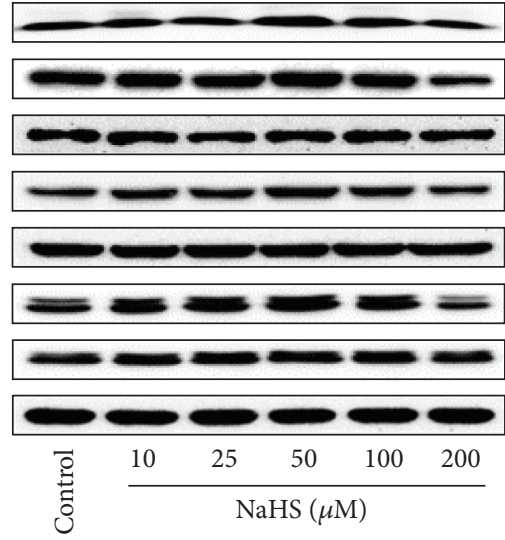

(a)

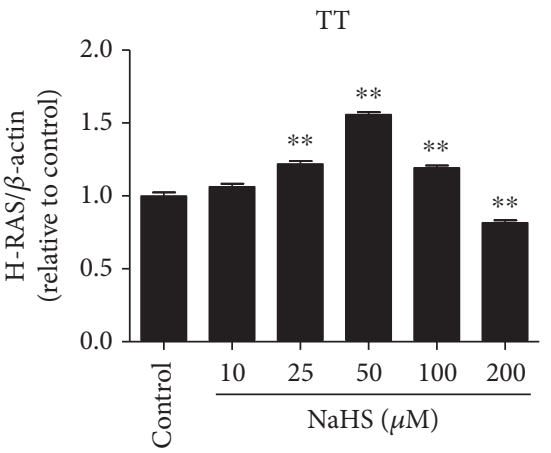

(b)

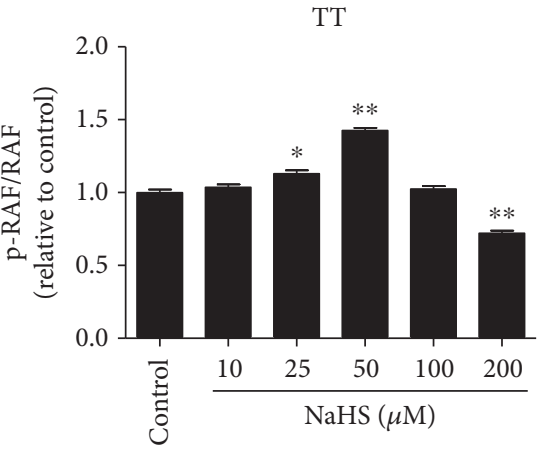

(c)

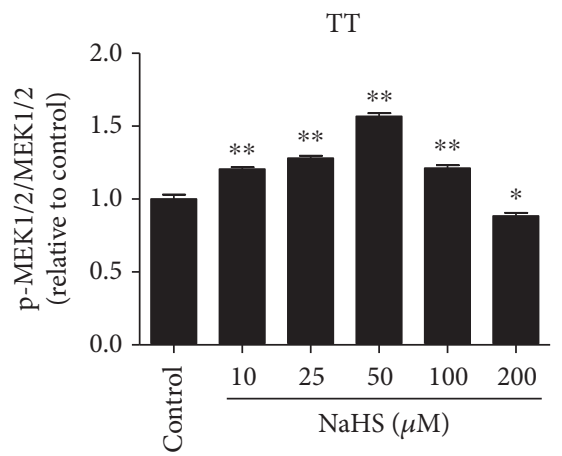

(d)

FIgUre 7: Continued.
ARO

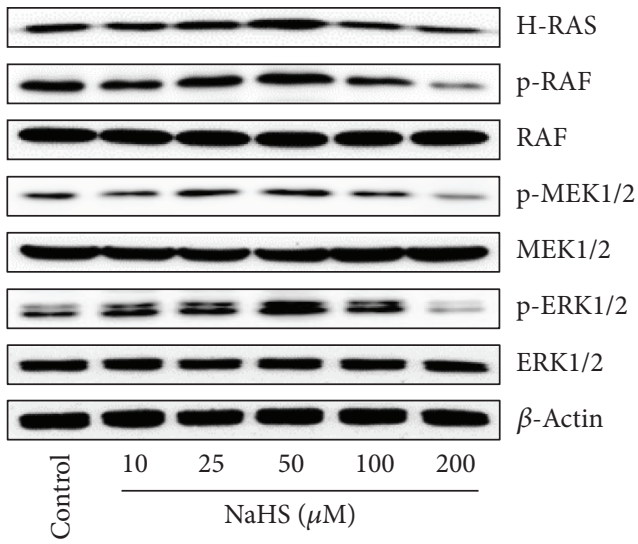

ARO

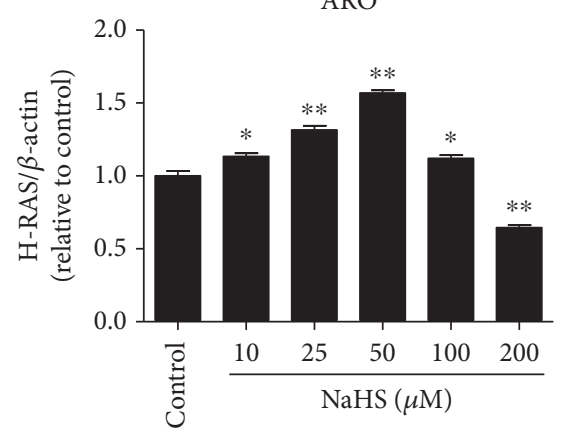

ARO

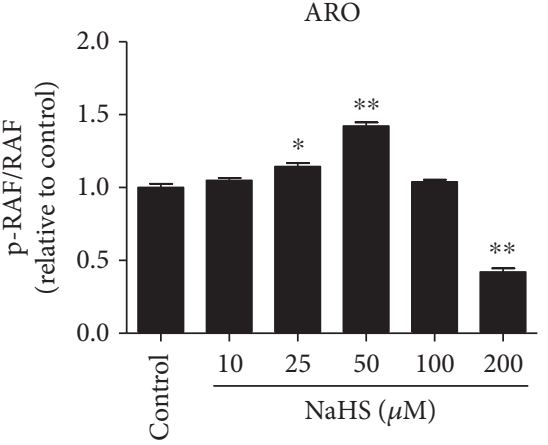

ARO

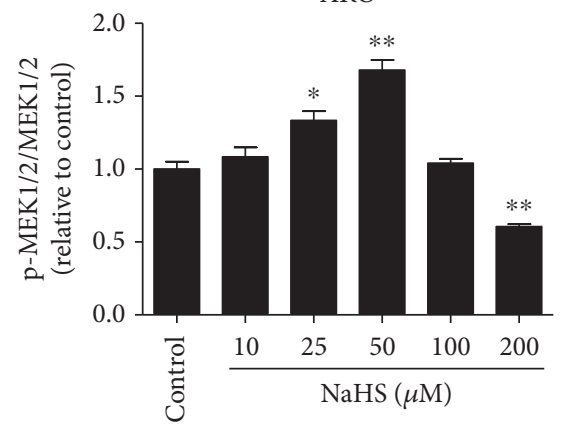



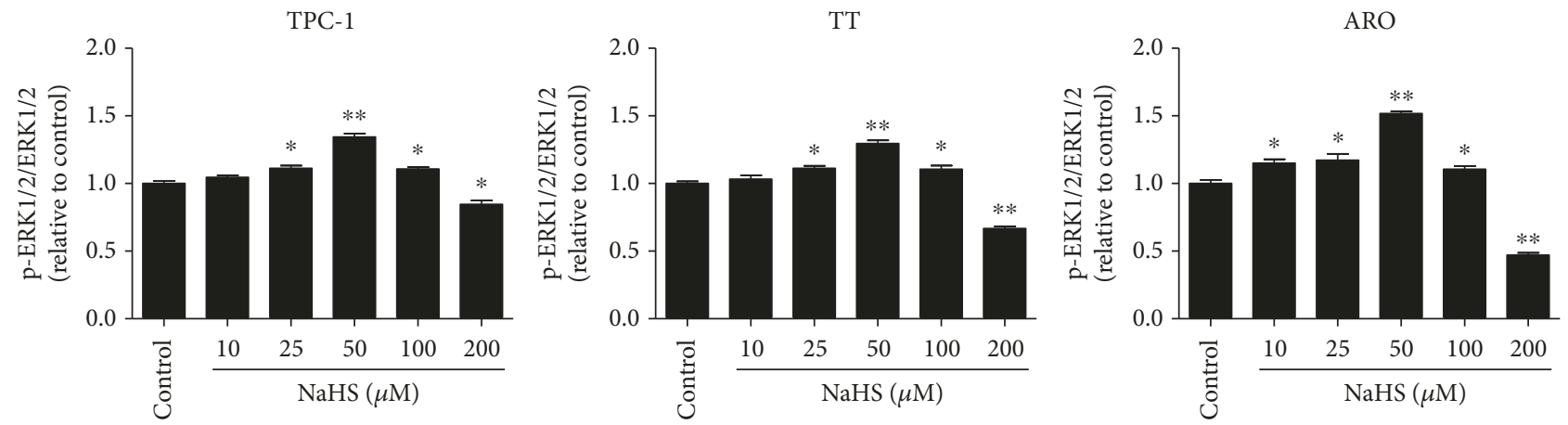

(e)

FIGURE 7: Effects of exogenous $\mathrm{H}_{2} \mathrm{~S}$ on the RAS/RAF/MEK/ERK signaling pathway in human thyroid carcinoma cells. (a) Western blotting analysis of the expressions of H-RAS, RAF, p-RAF, MEK1/2, p-MEK1/2, ERK1/2, and p-ERK1/2 in TPC-1, TT, and ARO cells. $\beta$-Actin was used as the loading control. (b-e) The intensities of the bands were quantified by densitometry analyses and normalized by the amount of $\beta$-actin, RAF, MEK1/2, and ERK1/2, respectively $(n=3) .{ }^{*} P<0.05,{ }^{* *} P<0.01$ compared with the control group.

$W$ is the dimension perpendicular to $L$ [27]. The tumor volume doubling time (TVDT) was calculated as TVDT $=$ $\log 2 / \log (V 2 / V 1) \times\left(T-T_{0}\right)$, where $V 2$ and $V 1$ are tumor volumes and $\left(T-T_{0}\right)$ is the time interval [33]. Then, the mice were sacrificed and tumors were excised and weighted. The inhibition rate (IR) of tumor growth was calculated as $\mathrm{IR}=[(A-B) / A] \times 100 \%$, where $A$ is the average tumor weight of the control group and $B$ is that of the treatment group [32].

2.12. Hematoxylin and Eosin (HE) Staining. Tumor samples were fixed in $10 \%$ neutral buffered formalin and embedded in paraffin. The specimens were sectioned at $5 \mu \mathrm{m}$ thickness and processed according to $\mathrm{HE}$ staining protocols [31]. Tumor tissues were observed using a Zeiss Axioskop 2 plus microscope.

2.13. Immunohistochemistry (IHC) and Evaluation. Tumor samples were stained with anti-Ki67 antibody (CST, Danvers, MA, USA). Ki67-positive tumor cells were observed with a Zeiss Axioskop 2 plus microscope. The proliferation index (PI) was determined as the ratio of the number of Ki67-positive cells to the total number of counted tumor cells [34]. Cluster of differentiation 31 (CD31) is a key biomarker for vascular endothelial cells, and its immunostaining density is represented by the tumor microvessel density (MVD) [35]. Tumor tissues were stained with CD31 antibody (CST, Danvers, MA, USA). Vessels were observed and counted by using a Zeiss Axioskop 2 plus microscope [31].

2.14. Statistical Analysis. Data are presented as mean \pm standard error of the mean (SEM). The differences between multiple groups were analyzed by one-way analysis of variance using SPSS 17.0 software, followed by Tukey's test. A $P$ value of less than 0.05 was considered to be statistically significant.

\section{Results}

3.1. Exogenous $\mathrm{H}_{2} \mathrm{~S}$ Regulates the Proliferation, Viability, Migration, and Invasion of Human Thyroid Carcinoma Cells. As shown in Figure 1, the proliferation and viability of TPC-1, TT, and ARO cells were enhanced by 25-50 $\mu \mathrm{M}$ $\mathrm{NaHS}$ and inhibited by $200 \mu \mathrm{M}$ NaHS. However, $\mathrm{H}_{2} \mathrm{~S}$ had no obvious effects on the proliferation and viability of Nthy-ori3-1 cells. In addition, 10-50 $\mu \mathrm{M}$ NaHS increased the migration capabilities of human thyroid carcinoma cells and $200 \mu \mathrm{M}$ NaHS exhibited reverse trends. $\mathrm{H}_{2} \mathrm{~S}$ did not affect the migration of human normal thyroid cells (Figure 2). These results indicate that $\mathrm{H}_{2} \mathrm{~S}$ is involved in the growth of human thyroid carcinoma cells. The protein levels of $\mathrm{H}_{2} \mathrm{~S}$-generating enzymes and $\mathrm{H}_{2} \mathrm{~S}$-degradating enzymes were further determined. The results showed that 25-50 $\mu \mathrm{M}$ NaHS increased the expression levels of CBS, while $200 \mu \mathrm{M}$ NaHS exerted reverse effects. Furthermore, $50 \mu \mathrm{M}$ NaHS increased the expression levels of SQR and TST, whereas $200 \mu \mathrm{M}$ NaHS showed reverse trends (Figure 3). Moreover, 25-50 $\mu \mathrm{M}$ NaHS increased the number of colonies, while $200 \mu \mathrm{M}$ NaHS exerted reverse effects (Figure 4). Transwell analysis showed that 10-50 $\mu \mathrm{M}$ NaHS improved the migration capacities and 25-50 $\mu \mathrm{M}$ NaHS increased the invasion capacities of human thyroid carcinoma cells. Treatment with $200 \mu \mathrm{M}$ NaHS inhibited the migration and invasion capacities of human thyroid carcinoma cells (Figure 5). These results suggest that exogenous $\mathrm{H}_{2} \mathrm{~S}$ plays an important role in regulating the proliferation, viability, migration, and invasion of human thyroid carcinoma cells.

\subsection{Exogenous $\mathrm{H}_{2} \mathrm{~S}$ Mediates the ROS/PI3K/AKT/mTOR} Signaling Pathway in Human Thyroid Carcinoma Cells. The $\mathrm{PI} 3 \mathrm{~K} / \mathrm{AKT} / \mathrm{mTOR}$ signaling pathway is a critical intracellular signaling cascade involved in a number of hallmarks of cancer, such as cell proliferation, survival, growth, motility, and metabolism [36, 37]. This pathway also plays a key role in many cancer-promoting aspects of the tumor environment, including angiogenesis and inflammatory cell recruitment [37]. Furthermore, it has been demonstrated that PI3K/Akt/mTOR cascade can be driven by ROS [38]. As shown in Figure 6, 25-50 $\mu \mathrm{M}$ NaHS decreased ROS levels and increased phosphorylations of PI3K, AKT, and mTOR, while $200 \mu \mathrm{M}$ NaHS showed opposite effects, indicating that exogenous $\mathrm{H}_{2} \mathrm{~S}$ regulates the 
TPC-1

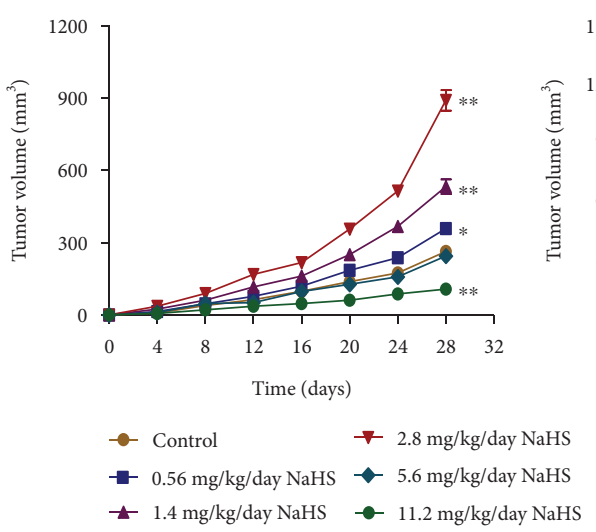

TPC-1

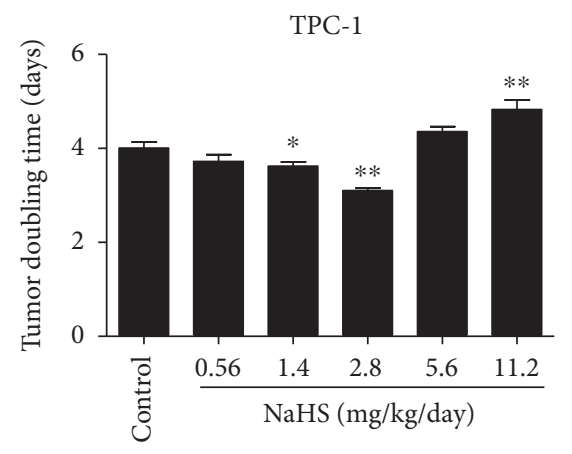

TPC-1

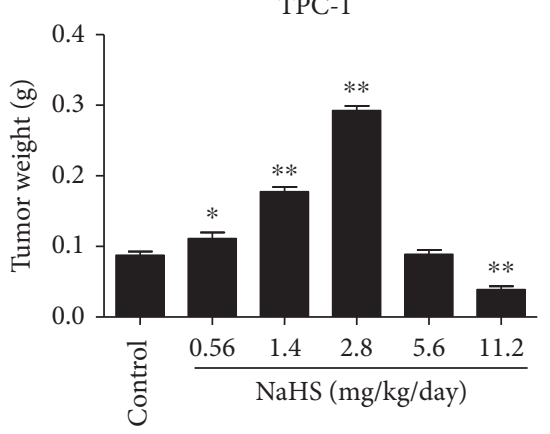

TPC-1

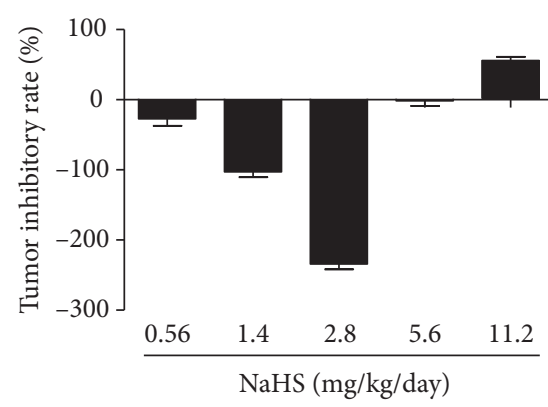

TT

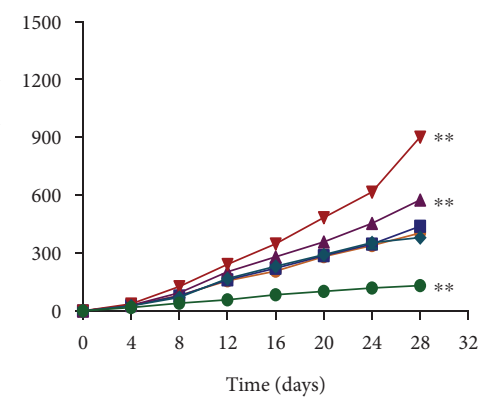

$\rightarrow$ Control $\quad \longrightarrow 2.8 \mathrm{mg} / \mathrm{kg} /$ day NaHS

- $0.56 \mathrm{mg} / \mathrm{kg} / \mathrm{day} \mathrm{NaHS} \longrightarrow 5.6 \mathrm{mg} / \mathrm{kg} /$ day NaHS

\ $1.4 \mathrm{mg} / \mathrm{kg} /$ day NaHS $\rightarrow 11.2 \mathrm{mg} / \mathrm{kg} / \mathrm{day} \mathrm{NaHS}$

(a)

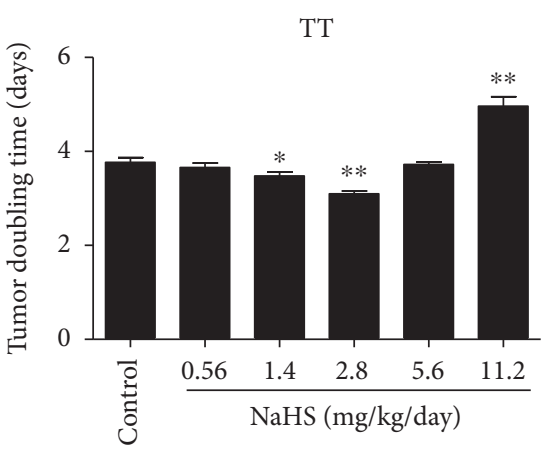

(b)

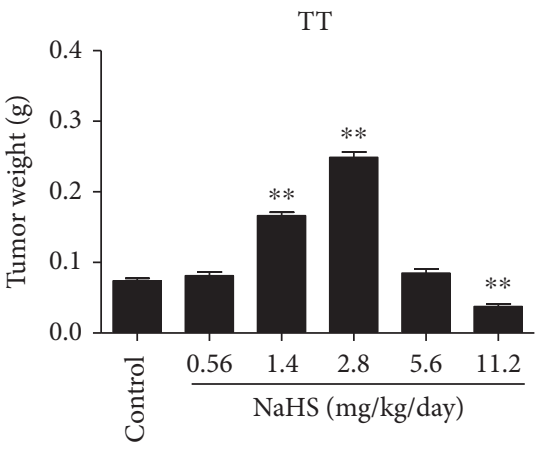

(c)

TT

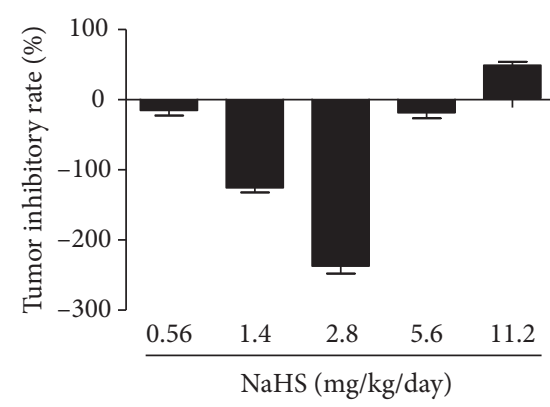

(d)
ARO

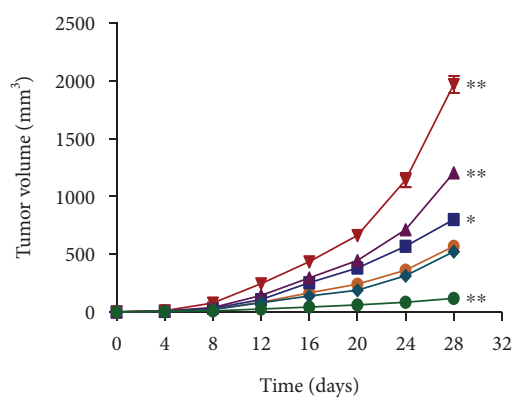

- Control $\quad-2.8 \mathrm{mg} / \mathrm{kg} / \mathrm{day} \mathrm{NaHS}$

- $0.56 \mathrm{mg} / \mathrm{kg} /$ day NaHS $\longrightarrow 5.6 \mathrm{mg} / \mathrm{kg} /$ day NaHS

$\leftarrow 1.4 \mathrm{mg} / \mathrm{kg} / \mathrm{day} \mathrm{NaHS} \longrightarrow 11.2 \mathrm{mg} / \mathrm{kg} /$ day NaHS

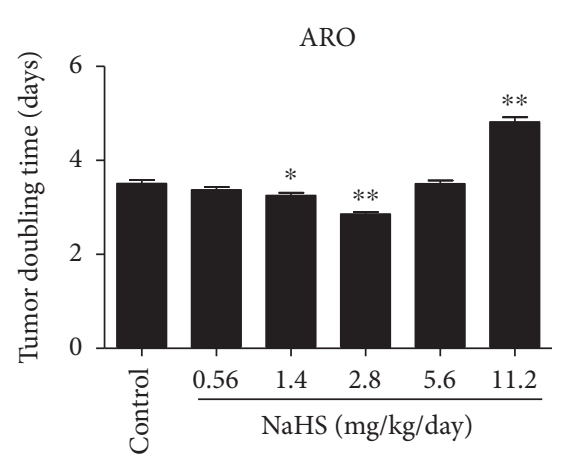

ARO

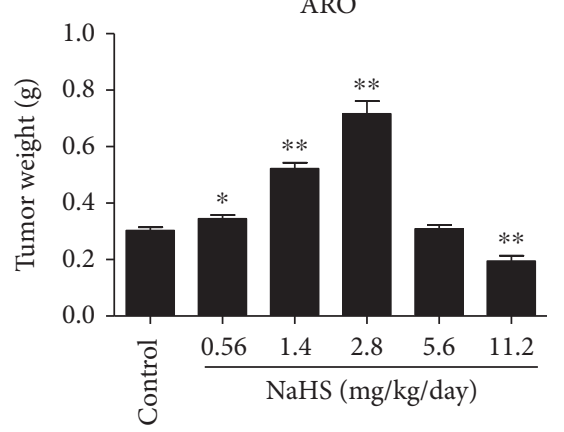

ARO

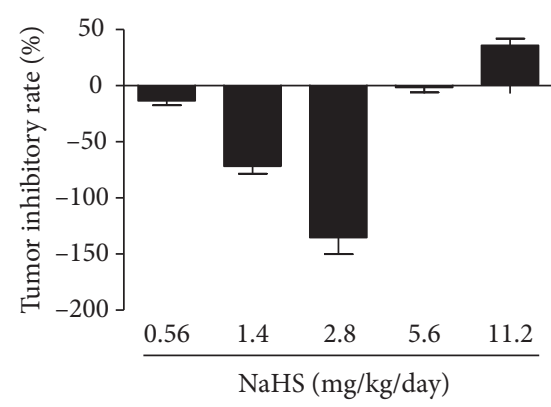

FIgURe 8: Continued. 

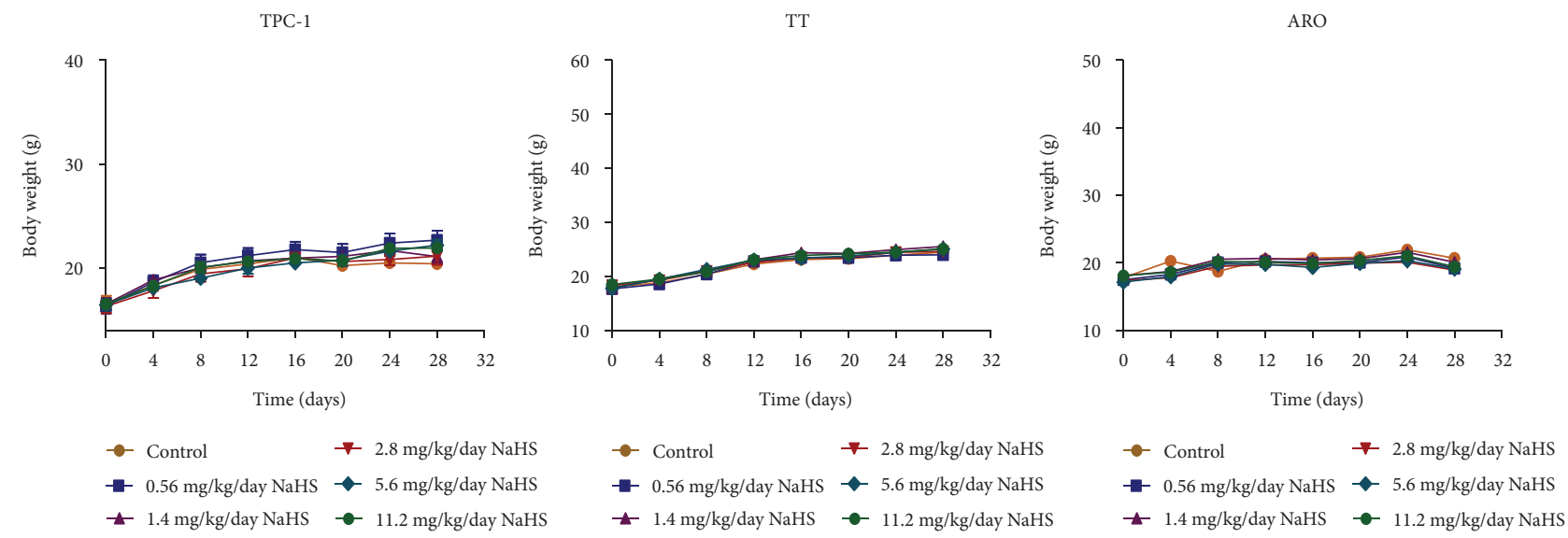

(e)

FIgURE 8: Effects of exogenous $\mathrm{H}_{2} \mathrm{~S}$ on the growth of human thyroid carcinoma xenograft tumors in nude mice. (a, b) The tumor volumes of TPC-1, TT, and ARO xenograft tumors were measured every day and the TVDT was calculated by the formula shown above $(n=8)$. (c, d) The tumors were weighed and the inhibition rates of tumor growth were calculated $(n=8)$. (e) The body weight change curve of each group during the experiment $(n=8) .{ }^{*} P<0.05,{ }^{*} P<0.01$ compared with the control group.

proliferation, viability, migration, and invasion of human thyroid carcinoma cells through the ROS/PI3K/AKT/mTOR signaling pathway.

3.3. Exogenous $\mathrm{H}_{2} \mathrm{~S}$ Mediates the RAS/RAF/MEK/ERK Signaling Pathway in Human Thyroid Carcinoma Cells. The RAS/RAF/MEK/ERK cascade is a key intracellular signaling pathway that regulates many physiological functions and cellular processes, including proliferation, apoptosis, survival, motility, differentiation, and metabolism [39-41]. Hyperactivation of the RAS/RAF/MEK/ERK signaling pathway has been regarded as a hallmark for driving tumorigenesis in a high percentage of human cancers $[42,43]$. As shown in Figure 7, treatment with 25-50 $\mu \mathrm{M}$ NaHS increased the protein levels of H-RAS, p-RAF, p-MEK1/2, and p-ERK1/2. However, administration of $200 \mu \mathrm{M}$ NaHS decreased the expression levels of these proteins. The results suggest that exogenous $\mathrm{H}_{2} \mathrm{~S}$ could regulate the proliferation, viability, migration, and invasion of human thyroid carcinoma cells via the RAS/RAF/MEK/ERK signaling pathway.

3.4. Exogenous $\mathrm{H}_{2} \mathrm{~S}$ Regulates the Growth and Angiogenesis of Human Thyroid Carcinoma Xenograft Tumors in Nude Mice. TPC-1, TT, and ARO cells have been successfully used to establish mouse tumor models in cancer research [44-46]. We therefore examined the effect of exogenous $\mathrm{H}_{2} \mathrm{~S}$ on the growth of human thyroid carcinoma xenograft in nude mice. Compared with the control group, treatment with 1.4-2.8 $\mathrm{mg} / \mathrm{kg} /$ day NaHS promoted the growth of xenograft tumors, while administration of $11.2 \mathrm{mg} / \mathrm{kg} /$ day NaHS showed opposite effects (Figures $8(\mathrm{a})-(\mathrm{d})$ ). However, there was no significant difference in body weight between each group (Figure 8(e)). IHC with the Ki67 antibody confirmed that the in vivo proliferation of human thyroid carcinoma cells was increased by treatment with $1.4-2.8 \mathrm{mg} / \mathrm{kg} /$ day NaHS and decreased by treatment with $11.2 \mathrm{mg} / \mathrm{kg} /$ day NaHS. Furthermore, the expression level of CD31 in human thyroid carcinoma xenograft tumors exhibited a similar trend (Figure 9). These results together suggest that exogenous $\mathrm{H}_{2} \mathrm{~S}$ modulates the growth and angiogenesis of human thyroid carcinoma xenograft tumors.

\section{Discussion}

$\mathrm{H}_{2} \mathrm{~S}$ has been considered the third gaseous signaling molecule and plays important roles in the progression of many types of cancer [5,26-28]. Thyroid cancer is one of the most common endocrine-related cancers with a rapid worldwide rise in incidence in the past few decades [24]. A recent study indicates that diallyl sulfide (an $\mathrm{H}_{2} \mathrm{~S}$ donor) could decrease cell proliferation and induce apoptosis via mitochondrial signaling pathway in anaplastic thyroid carcinoma cells [47]. However, whether $\mathrm{H}_{2} \mathrm{~S}$ is involved in the growth of human thyroid carcinoma cells remains unknown. Human thyroid carcinoma cell lines TPC-1, TT, and ARO cells have been widely implicated in establishing tumor-bearing animal models [44-46]. In this study, TPC-1, TT, and ARO cells were used to evaluate the effects of exogenous $\mathrm{H}_{2} \mathrm{~S}$ both in vitro and in vivo. The results showed that administration of $25-50 \mu \mathrm{M}$ NaHS promoted the proliferation and viability, as well as increased the migration and invasion capabilities of TPC-1, TT, and ARO cells when compared with the control group, whereas treatment with $200 \mu \mathrm{M}$ NaHS exhibited completely opposite effects. However, $\mathrm{H}_{2} \mathrm{~S}$ had no obvious effects on the proliferation, viability, and migration of Nthy-ori3-1 cells. In addition, 25-50 $\mu \mathrm{M}$ NaHS increased the expression levels of CBS, while $200 \mu \mathrm{M}$ NaHS exerted reverse effects, suggesting that $\mathrm{CBS}$ may mediate the effects of $\mathrm{H}_{2} \mathrm{~S}$ on the growth of human thyroid carcinoma cells. Knockout or knockdown experiments could be performed to clarify the mechanism of action of CBS in the procession of thyroid carcinoma. Treatment with $50 \mu \mathrm{M}$ NaHS increased the expression levels of SQR and TST, whereas $200 \mu \mathrm{M}$ NaHS showed reverse trends. These results 
HE

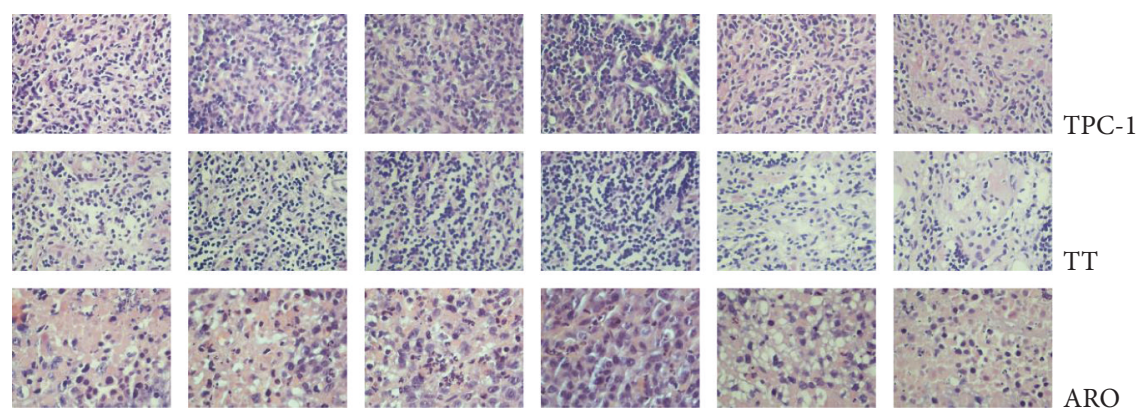

(a)

Ki67

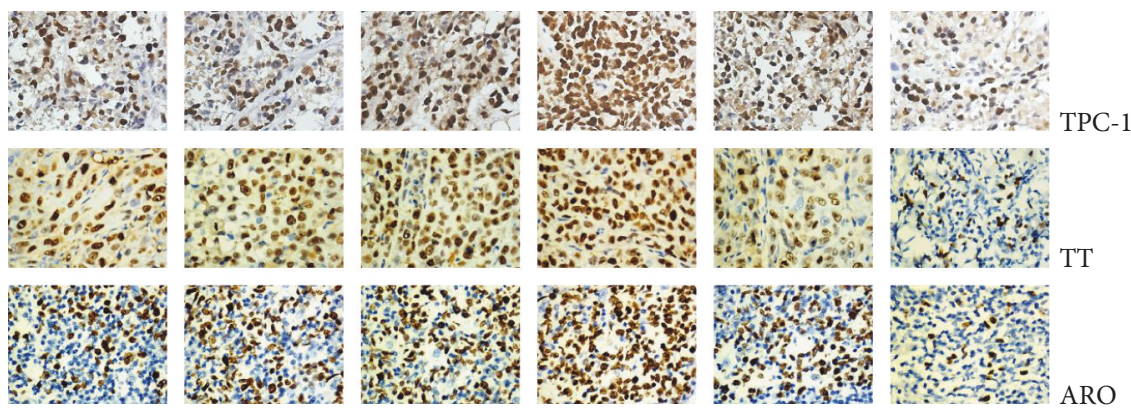

(b)

CD31

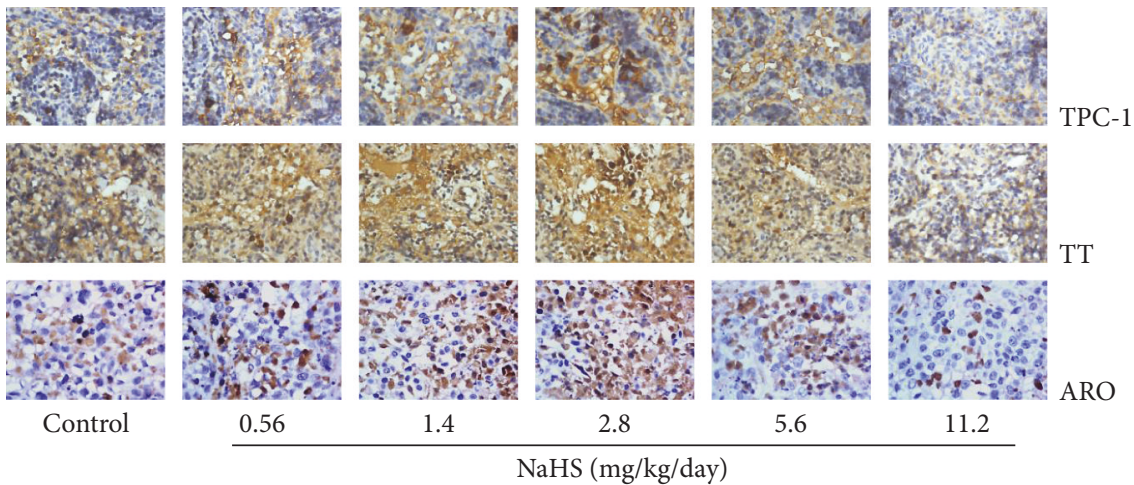

(c)
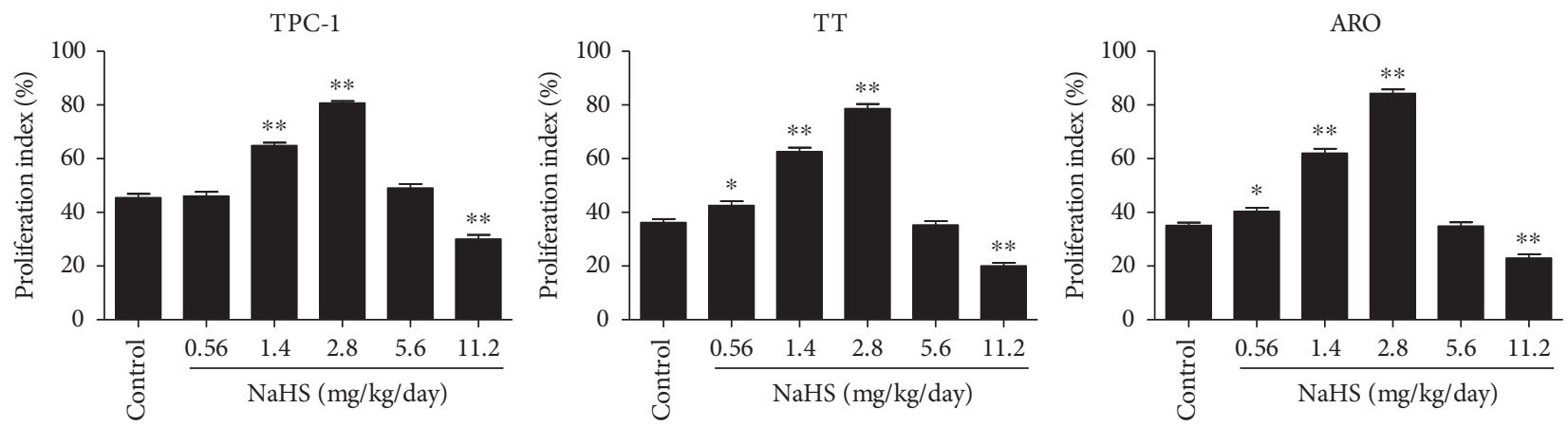

(d)

Figure 9: Continued. 

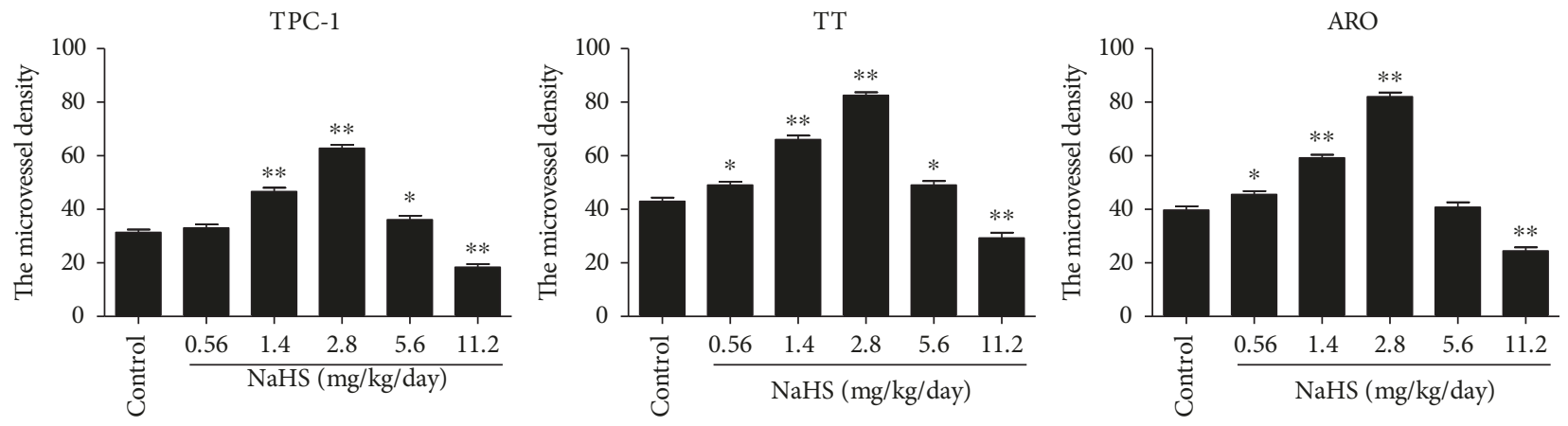

(e)

FIGURE 9: Effects of exogenous $\mathrm{H}_{2} \mathrm{~S}$ on the PI and MVD of human thyroid carcinoma xenograft tumors. (a-c) Representative photographs of HE, Ki67, and CD31 staining in TPC-1, TT, and ARO xenograft tumors; original magnification $\times 400$. (d, e) The PI and MVD were calculated $(n=6) .{ }^{*} P<0.05,{ }^{* *} P<0.01$ compared with the control group.

together suggest that exogenous $\mathrm{H}_{2} \mathrm{~S}$ plays important roles in the proliferation, viability, migration, and invasion of human thyroid carcinoma cells. Whether CBS-derived $\mathrm{H}_{2} \mathrm{~S}$ could mediate the growth of human thyroid carcinoma cells needs to be further investigated.

The PI3K/AKT/mTOR signaling pathway is involved in cell growth, survival, metabolism, motility, and angiogenesis $[48,49]$. PI3K activates the threonine/serine kinase AKT, which could phosphorylate and activate $\mathrm{MTOR}$ via a cascade of regulators [48]. The $\mathrm{PI} 3 \mathrm{~K} / \mathrm{AKT} / \mathrm{mTOR}$ pathway is one of the most frequently dysregulated pathways in tumor progression, which makes this pathway an attractive target for cancer therapy $[48,50,51]$. It has been reported that ROS could serve as upstream regulators of PI3K, Akt, and mTOR $[38,52,53]$. Furthermore, intracellular ROS play vital roles in $\mathrm{PI} 3 \mathrm{~K} / \mathrm{AKT} / \mathrm{mTOR}$ inactivation in human THP-1 monocytes [54] and human prostate cancer cells [55]. A recent study indicates that AKT activity is upregulated in aggressive thyroid cancers where it promotes proliferation and invasion [56]. Furthermore, melanoregulin has been shown to regulate the invasion and proliferation of thyroid cancer cells via $\mathrm{PI} 3 \mathrm{~K} / \mathrm{AKT} / \mathrm{mTOR}$ pathway [57]. Another study suggests that $0.1 \mathrm{mM} \mathrm{Na}_{2} \mathrm{~S}$ (an $\mathrm{H}_{2} \mathrm{~S}$ donor) decreases ROS formation, however, $0.5 \mathrm{mM} \mathrm{Na}_{2} \mathrm{~S}$ induces an increase in ROS formation in HeLa cells, indicating that relatively low doses of $\mathrm{H}_{2} \mathrm{~S}$ can inhibit the oxidative stress and relatively high levels of $\mathrm{H}_{2} \mathrm{~S}$ show opposite effects [58]. In addition, $\mathrm{H}_{2} \mathrm{~S}$ has exerted multiple biological effects on HCC cells by inhibiting the PI3K/Akt/mTOR pathway [59]. Our results demonstrated that $25-50 \mu \mathrm{M}$ NaHS promoted the proliferation, viability, migration, and invasion of human thyroid carcinoma cells by downregulating ROS levels and upregulating phosphorylations of PI3K, AKT, and mTOR. However, administration of $200 \mu \mathrm{M}$ NaHS decreased the expression levels of these proteins. The results indicate that exogenous $\mathrm{H}_{2} \mathrm{~S}$ regulates the growth of human thyroid carcinoma cells through the ROS/PI3K/AKT/mTOR signaling pathway.

The RAS/RAF/MEK/ERK pathway comprises three dualspecific protein kinases RAF, MEK, ERK, and the G-protein RAS [60]. The binding of different ligands to receptor tyrosine kinases at the cell surface can induce the activation of RAS which in turn activates RAF, MEK, and ERK [60, 61]. The activated ERK translocates into the nucleus and activates transcription factors to induce a number of cellular functions $[39,62]$. The RAS/RAF/MEK/ERK pathway plays key roles in cancer development, maintenance, and progression, which may contribute to drug resistance and poorer prognosis [63]. It has been shown that the RAS/RAF/MEK/ERK pathway is one of the most frequently activated oncogenic signaling pathways in thyroid cancer [64]. A previous study indicates that the majority of differentiated thyroid cancer patients exhibit a detectable genetic alteration affecting the RAF/MEK/ERK pathway [65]. In addition, diallyl disulfide (DADS) can suppress the growth of human esophageal xenograft tumors through RAF/MEK/ERK and mitochondria-dependent pathways [66]. Considering $\mathrm{H}_{2} \mathrm{~S}$ can be released by DADS [67], whether $\mathrm{H}_{2} \mathrm{~S}$ mediates the effect of DADS on the growth of human esophageal cancer cells needs to be further investigated. Our results showed that 25-50 $\mu \mathrm{M}$ NaHS increased the protein levels of H-RAS, p-RAF, p-MEK1/2, and p-ERK1/2, while treatment with $200 \mu \mathrm{M}$ NaHS showed opposite effects. The results suggest that exogenous $\mathrm{H}_{2} \mathrm{~S}$ regulates the proliferation, viability, migration, and invasion of human thyroid carcinoma cells via the RAS/RAF/MEK/ERK signaling pathway.

TPC-1, TT, and ARO cells have been widely adopted to establish subcutaneous xenograft models [44-46]. We therefore examined the effect of exogenous $\mathrm{H}_{2} \mathrm{~S}$ on the growth of human thyroid carcinoma xenograft tumors in BALB/c nude mice. Compared with the control group, $1.4-2.8 \mathrm{mg} / \mathrm{kg} /$ day NaHS promoted the growth of xenograft tumors, while administration of $11.2 \mathrm{mg} / \mathrm{kg} /$ day NaHS exhibited the inhibitory effects on the growth of xenograft tumors. Ki67 is a key proliferative marker and has been widely used in detecting the proliferation of malignant cells $[34,68]$. The results indicated that the expression of Ki67 was increased by treatment with $1.4-2.8 \mathrm{mg} / \mathrm{kg} /$ day $\mathrm{NaHS}$ and decreased by treatment with $11.2 \mathrm{mg} / \mathrm{kg} /$ day NaHS, which were in agreement with the findings in vitro. CD31 has been regarded as an ideal biomarker for vascular endothelial cells, and its density is 
represented by the tumor MVD [35, 69]. The protein expression of CD31 in each group showed a similar trend. In sum, these results indicate that exogenous $\mathrm{H}_{2} \mathrm{~S}$ could modulate the growth and angiogenesis of human thyroid carcinoma xenograft tumors.

In conclusion, our results demonstrate that exogenous $\mathrm{H}_{2} \mathrm{~S}$ is able to regulate the growth of human thyroid carcinoma cells both in vitro and in vivo. Novel $\mathrm{H}_{2} \mathrm{~S}$-releasing donors/drugs can be designed and applied for the treatment of thyroid cancer.

\section{Data Availability}

The raw data used to support the findings of this study are available from the corresponding authors upon request.

\section{Conflicts of Interest}

The authors declare that they have no conflicts of interest related to this work.

\section{Acknowledgments}

This work was supported by grants from the National Natural Science Foundation of China (Nos. 81802718, U1504817, and 81870591), the Foundation of Science \& Technology Department of Henan Province, China (Nos. 182102310335, 162300410233 , and 162300410036), the Natural Science Foundation of Education Department of Henan Province, China (No. 15A310017), the Science Foundation of Kaifeng City, China (Nos. 1608004, 1703016), and the Science Foundation of Henan University, China (No. yqpy20170044).

\section{References}

[1] C. Szabo, "Gasotransmitters in cancer: from pathophysiology to experimental therapy," Nature Reviews Drug Discovery, vol. 15, no. 3, pp. 185-203, 2016.

[2] M. D. Hartle and M. D. Pluth, "A practical guide to working with $\mathrm{H} 2 \mathrm{~S}$ at the interface of chemistry and biology," Chemical Society Reviews, vol. 45, no. 22, pp. 6108-6117, 2016.

[3] Y. J. Peng, X. Zhang, A. Gridina et al., "Complementary roles of gasotransmitters CO and H2S in sleep apnea," Proceedings of the National Academy of Sciences, vol. 114, no. 6, pp. 1413-1418, 2017.

[4] B. D. Paul and S. H. Snyder, "H2S signalling through protein sulfhydration and beyond," Nature Reviews Molecular Cell Biology, vol. 13, no. 8, pp. 499-507, 2012.

[5] C. Szabo, C. Coletta, C. Chao et al., "Tumor-derived hydrogen sulfide, produced by cystathionine- $\beta$-synthase, stimulates bioenergetics, cell proliferation, and angiogenesis in colon cancer," Proceedings of the National Academy of Sciences, vol. 110, no. 30, pp. 12474-12479, 2013.

[6] M. R. Filipovic, J. Zivanovic, B. Alvarez, and R. Banerjee, "Chemical biology of $\mathrm{H}_{2} \mathrm{~S}$ signaling through persulfidation," Chemical Reviews, vol. 118, no. 3, pp. 1253-1337, 2018.

[7] N. Nagahara, "Regulation of mercaptopyruvate sulfurtransferase activity via intrasubunit and intersubunit redox-sensing switches," Antioxid Redox Signal., vol. 19, no. 15, pp. 17921802, 2013.
[8] K. Módis, C. Coletta, K. Erdélyi, A. Papapetropoulos, and C. Szabo, "Intramitochondrial hydrogen sulfide production by 3-mercaptopyruvate sulfurtransferase maintains mitochondrial electron flow and supports cellular bioenergetics," FASEB Journal, vol. 27, no. 2, pp. 601-611, 2013.

[9] N. Shibuya, S. Koike, M. Tanaka et al., "A novel pathway for the production of hydrogen sulfide from D-cysteine in mammalian cells," Nature Communications, vol. 4, no. 1, 2013.

[10] T. V. Mishanina, M. Libiad, and R. Banerjee, "Biogenesis of reactive sulfur species for signaling by hydrogen sulfide oxidation pathways," Nature Chemical Biology, vol. 11, no. 7, pp. 457-464, 2015.

[11] X. Shen, M. Carlström, S. Borniquel, C. Jädert, C. G. Kevil, and J. O. Lundberg, "Microbial regulation of host hydrogen sulfide bioavailability and metabolism," Free Radical Biology and Medicine, vol. 60, pp. 195-200, 2013.

[12] N. Shibuya and H. Kimura, "Production of hydrogen sulfide from d-cysteine and its therapeutic potential," Frontiers in Endocrinology, vol. 4, 2013.

[13] D. Wu, J. Wang, H. Li, M. Xue, A. Ji, and Y.Li, "Role of hydrogen sulfide in ischemia-reperfusion injury," Oxidative Medicine and Cellular Longevity, vol. 2015, Article ID 186908, 16 pages, 2015.

[14] W. Cai, M. Wang, P. Moore, H. Jin, T. Yao, and Y. Zhu, "The novel proangiogenic effect of hydrogen sulfide is dependent on Akt phosphorylation," Cardiovascular Research, vol. 76, no. 1, pp. 29-40, 2007.

[15] G. Yang, L. Wu, B. Jiang et al., " $\mathrm{H}_{2} \mathrm{~S}$ as a physiologic vasorelaxant: hypertension in mice with deletion of cystathionine gamma-lyase," Science., vol. 322, no. 5901, pp. 587-590, 2008.

[16] D. K. Ma, R. Vozdek, N. Bhatla, and H. R. Horvitz, "CYSL1 interacts with the $\mathrm{O}_{2}$-sensing hydroxylase EGL-9 to promote $\mathrm{H}_{2} \mathrm{~S}$-modulated hypoxia-induced behavioral plasticity in C. elegans," Neuron., vol. 73, no. 5, pp. 925-940, 2012.

[17] M. Fu, W. Zhang, L. Wu, G. Yang, H. Li, and R. Wang, "Hydrogen sulfide $\left(\mathrm{H}_{2} \mathrm{~S}\right)$ metabolism in mitochondria and its regulatory role in energy production," Proceedings of the National Academy of Sciences, vol. 109, no. 8, pp. 2943-2948, 2012.

[18] J. Pichette and J. Gagnon, "Implications of hydrogen sulfide in glucose regulation: how $\mathrm{H}_{2} \mathrm{~S}$ can alter glucose homeostasis through metabolic hormones," Oxidative Medicine and Cellular Longevity, vol. 2016, Article ID 3285074, 5 pages, 2016.

[19] S. Mani, H. Li, A. Untereiner et al., "Decreased endogenous production of hydrogen sulfide accelerates atherosclerosis," Circulation., vol. 127, no. 25, pp. 2523-2534, 2013.

[20] Z. Cheng, V. N. S. Garikipati, E. Nickoloff et al., "Restoration of hydrogen sulfide production in diabetic mice improves reparative function of bone marrow cells," Circulation., vol. 134, no. 19, pp. 1467-1483, 2016.

[21] P. Wang, L. Wu, Y. Ju et al., "Age-dependent allergic asthma development and cystathionine gamma-lyase deficiency," Antioxid Redox Signal., vol. 27, no. 13, pp. 931-944, 2017.

[22] K. Wang, S. Ahmad, M. Cai et al., "Dysregulation of hydrogen sulfide producing enzyme cystathionine $\gamma$-lyase contributes to maternal hypertension and placental abnormalities in preeclampsia," Circulation., vol. 127, no. 25, pp. 2514-2522, 2013.

[23] B. D. Paul, J. I. Sbodio, R. Xu et al., "Cystathionine $\gamma$-lyase deficiency mediates neurodegeneration in Huntington's disease," Nature, vol. 509, no. 7498, pp. 96-100, 2014. 
[24] M. Xing, B. R. Haugen, and M. Schlumberger, "Progress in molecular-based management of differentiated thyroid cancer," Lancet., vol. 381, no. 9871, pp. 1058-1069, 2013.

[25] X. Meng, D. H. Kong, N. Li et al., "Knockdown of BAG3 induces epithelial-mesenchymal transition in thyroid cancer cells through ZEB1 activation," Cell Death \& Disease, vol. 5, no. 2, p. e1092, 2014.

[26] P. De Cicco, E. Panza, G. Ercolano et al., "ATB-346, a novel hydrogen sulfide-releasing anti-inflammatory drug, induces apoptosis of human melanoma cells and inhibits melanoma development in vivo," Pharmacological Research, vol. 114, pp. 67-73, 2016.

[27] D. Wu, M. Li, W. Tian et al., "Hydrogen sulfide acts as a double-edged sword in human hepatocellular carcinoma cells through EGFR/ERK/MMP-2 and PTEN/AKT signaling pathways," Scientific Reports, vol. 7, no. 1, p. 5134, 2017.

[28] D. Wu, W. Si, M. Wang, S. Lv, A. Ji, and Y. Li, "Hydrogen sulfide in cancer: friend or foe?," Nitric Oxide., vol. 50, pp. 38-45, 2015.

[29] D.D.Wu,Y.R.Gao, T.Lietal., "PEST-containingnuclearprotein mediates the proliferation, migration, and invasion of human neuroblastoma cells through MAPK and PI3K/AKT/mTOR signaling pathways," BMC Cancer., vol. 18, no. 1, p. 499, 2018.

[30] D. Wu, N. Luo, L. Wang et al., "Hydrogen sulfide ameliorates chronic renal failure in rats by inhibiting apoptosis and inflammation through ROS/MAPK and NF- $\kappa$ B signaling pathways," Scientific Reports, vol. 7, no. 1, p. 455, 2017.

[31] D. D. Wu, S. Y. Liu, Y. R. Gao et al., "Tumour necrosis factor$\alpha$-induced protein 8 -like 2 is a novel regulator of proliferation, migration, and invasion in human rectal adenocarcinoma cells," Journal of Cellular and Molecular Medicine, vol. 23, no. 3, pp. 1698-1713, 2019.

[32] D. Wu, Y. Gao, L. Chen et al., "Anti-tumor effects of a novel chimeric peptide on S180 and H22 xenografts bearing nude mice," Peptides., vol. 31, no. 5, pp. 850-864, 2010.

[33] B. M. Ellingson, H. N. Nguyen, A. Lai et al., "Contrast-enhancing tumor growth dynamics of preoperative, treatment-naive human glioblastoma," Cancer., vol. 122, no. 11, pp. 17181727, 2016.

[34] B. Keam, S. A. Im, K. H. Lee et al., "Ki-67 can be used for further classification of triple negative breast cancer into two subtypes with different response and prognosis," Breast Cancer Research, vol. 13, no. 2, p. R22, 2011.

[35] S. M. Tolaney, Y. Boucher, D. G. Duda et al., "Role of vascular density and normalization in response to neoadjuvant bevacizumab and chemotherapy in breast cancer patients," Proceedings of the National Academy of Sciences, vol. 112, no. 46, pp. 14325-14330, 2015.

[36] L. M. Thorpe, H. Yuzugullu, and J. J. Zhao, "PI3K in cancer: divergent roles of isoforms, modes of activation and therapeutic targeting," Nat Rev Cancer., vol. 15, no. 1, pp. 7-24, 2015.

[37] D. A. Fruman and C. Rommel, "PI3K and cancer: lessons, challenges and opportunities," Nature Reviews Drug Discovery, vol. 13, no. 2, pp. 140-156, 2014.

[38] J. E. Le Belle, N. M. Orozco, A. A. Paucar et al., "Proliferative neural stem cells have high endogenous ROS levels that regulate self-renewal and neurogenesis in a PI3K/Akt-dependant manner," Cell Stem Cell., vol. 8, no. 1, pp. 59-71, 2011.

[39] M. Kitagawa, P. J. Liao, K. H. Lee et al., "Dual blockade of the lipid kinase PIP4Ks and mitotic pathways leads to cancer- selective lethality," Nature Communications, vol. 8, no. 1, p. 2200, 2017.

[40] J. Xu, N. Pfarr, V. Endris et al., "Molecular signaling in multiple myeloma: association of RAS/RAF mutations and MEK/ERK pathway activation," Oncogenesis., vol. 6, no. 5, p. e337, 2017.

[41] Z. Lin, C. Zhang, M. Zhang et al., "Targeting cadherin-17 inactivates Ras/Raf/MEK/ERK signaling and inhibits cell proliferation in gastric cancer," PLoS One., vol. 9, no. 1, article e85296, 2014.

[42] J. Peng and A. Gassama-Diagne, "Apicobasal polarity and Ras/Raf/MEK/ERK signalling in cancer,” Gut., vol. 66, no. 6, pp. 986-987, 2017.

[43] A. A. Samatar and P. I. Poulikakos, "Targeting RAS-ERK signalling in cancer: promises and challenges," Nature Reviews Drug Discovery, vol. 13, no. 12, pp. 928-942, 2014.

[44] X. Li, Z. Li, Y. Song, W. Liu, and Z. Liu, “The mTOR kinase inhibitor CZ415 inhibits human papillary thyroid carcinoma cell growth," Cellular Physiology and Biochemistry, vol. 46, no. 2, pp. 579-590, 2018.

[45] L. Kucerova, M. Matuskova, K. Hlubinova et al., "Bystander cytotoxicity in human medullary thyroid carcinoma cells mediated by fusion yeast cytosine deaminase and 5-fluorocytosine," Cancer Letters, vol. 311, no. 1, pp. 101-112, 2011.

[46] Y. So, Y. J. Lee, W. W. Lee, and J.-K. Chung, "Determination of the optimal time for radioiodine therapy in anaplastic thyroid carcinoma using the adenovirus-mediated transfer of sodium iodide symporter gene," Oncology Reports, vol. 29, no. 4, pp. 1666-1670, 2013.

[47] H. A. Shin, Y. Y. Cha, M. S. Park, J. M. Kim, and Y. C. Lim, "Diallyl sulfide induces growth inhibition and apoptosis of anaplastic thyroid cancer cells by mitochondrial signaling pathway," Oral Oncology, vol. 46, no. 4, pp. e15-e18, 2010.

[48] J. Rodon, R. Dienstmann, V. Serra, and J. Tabernero, "Development of PI3K inhibitors: lessons learned from early clinical trials," Nature Reviews Clinical Oncology, vol. 10, no. 3, pp. 143-153, 2013.

[49] A. Perl, "Activation of mTOR (mechanistic target of rapamycin) in rheumatic diseases," Nature Reviews Rheumatology, vol. 12, no. 3, pp. 169-182, 2016.

[50] F. Janku, T. A. Yap, and F. Meric-Bernstam, "Targeting the PI3K pathway in cancer: are we making headway?," Nature Reviews Clinical Oncology, vol. 15, no. 5, pp. 273-291, 2018.

[51] J. Dancey, "mTOR signaling and drug development in cancer," Nature Reviews Clinical Oncology, vol. 7, no. 4, pp. 209-219, 2010.

[52] L. Chen, P. Liu, X. Feng, and C. Ma, "Salidroside suppressing LPS-induced myocardial injury by inhibiting ROS-mediated $\mathrm{PI} 3 \mathrm{~K} / \mathrm{Akt} / \mathrm{mTOR}$ pathway in vitro and in vivo," Journal of Cellular and Molecular Medicine, vol. 21, no. 12, pp. 3178-3189, 2017.

[53] L. Zhang, H. Wang, J. Xu, J. Zhu, and K. Ding, "Inhibition of cathepsin S induces autophagy and apoptosis in human glioblastoma cell lines through ROS-mediated PI3K/AKT/mTOR/p70S6K and JNK signaling pathways," Toxicol Letters, vol. 228, no. 3, pp. 248-259, 2014.

[54] Y. Jiang, J. Kou, X. Han et al., "ROS-dependent activation of autophagy through the PI3K/Akt/mTOR pathway is induced by hydroxysafflor yellow A-sonodynamic therapy in THP-1 macrophages," Oxidative Medicine and Cellular Longevity, vol. 2017, Article ID 8519169, 16 pages, 2017. 
[55] K.Y.Kim,K.I.Park,S.H.Kim etal., "Inhibition of autophagy promotes salinomycin-induced apoptosis via reactive oxygen species-mediated PI3K/AKT/mTOR and ERK/p38 MAPKdependent signaling in human prostate cancer cells," International Journal of Molecular Sciences, vol. 18, no. 5, p. 1088, 2017.

[56] D.R.Matson,H.Hardin, D. Buehler, and R.V.Lloyd, “AKTactivity is elevated in aggressive thyroid neoplasms where it promotes proliferation and invasion," Experimentaland MolecularPathology, vol. 103, no. 3, pp. 288-293, 2017.

[57] X. Meng, Y.Dong, X. Yu et al., "MREG suppresses thyroid cancer cell invasion and proliferation by inhibiting Akt-mTOR signaling," Biochemical and Biophysical Research Communications, vol. 491, no. 1, pp. 72-78, 2017.

[58] R. Wedmann, S. Bertlein, I. Macinkovic et al., "Working with " $\mathrm{H}_{2} \mathrm{~S}$ ": facts and apparent artifacts," Nitric Oxide., vol. 41, pp. 85-96, 2014.

[59] S. S. Wang, Y. H. Chen, N. Chen et al., "Hydrogen sulfide promotes autophagy of hepatocellular carcinoma cells through the PI3K/Akt/mTOR signaling pathway," Cell Death \& Disease, vol. 8, no. 3, p. e2688, 2017.

[60] T. Knight and J. A. E. Irving, "Ras/Raf/MEK/ERK pathway activation in childhood acute lymphoblastic leukemia and its therapeutic targeting," Frontiers in Oncology, vol. 4, p. 160, 2014.

[61] M. Gourlaouen, J. C. Welti, N. S. Vasudev, and A. R. Reynolds, "Essential role for endocytosis in the growth factor-stimulated activation of ERK1/2 in endothelial cells," Journal of Biological Chemistry, vol. 288, no. 11, pp. 7467-7480, 2013.

[62] J. Göke, Y. S. Chan, J. Yan, M. Vingron, and H. H. Ng, "Genome-wide kinase-chromatin interactions reveal the regulatory network of ERK signaling in human embryonic stem cells," Molecular Cell, vol. 50, no. 6, pp. 844-855, 2013.

[63] R. Mandal, S. Becker, and K. Strebhardt, "Stamping out RAF and MEK1/2 to inhibit the ERK1/2 pathway: an emerging threat to anticancer therapy," Oncogene., vol. 35 , no. 20 , pp. 2547-2561, 2016.

[64] M. Xing, "Molecular pathogenesis and mechanisms of thyroid cancer," Nature Rev Cancer., vol. 13, no. 3, pp. 184-199, 2013.

[65] N. Jin, T. Jiang, D. M. Rosen, B. D. Nelkin, and D. W. Ball, "Synergistic action of a RAF inhibitor and a dual PI3K/mTOR inhibitor in thyroid cancer," Clinical Cancer Research, vol. 17, no. 20, pp. 6482-6489, 2011.

[66] X. Yin, J. Zhang, X. Li et al., "DADS suppresses human esophageal xenograft tumors through RAF/MEK/ERK and mitochondria-dependent pathways," International Journal of Molecular Sciences, vol. 15, no. 7, pp. 12422-12441, 2014.

[67] Y. R. Cai and C. H. Hu, "Computational study of $\mathrm{H}_{2} \mathrm{~S}$ release in reactions of diallyl polysulfides with thiols," The Journal of Physical Chemistry B, vol. 121, no. 26, pp. 6359-6366, 2017.

[68] C. Ricciardelli, N. A. Lokman, I. Sabit et al., "Novel ex vivo ovarian cancer tissue explant assay for prediction of chemosensitivity and response to novel therapeutics," Cancer Letters, vol. 421, pp. 51-58, 2018.

[69] R. Hatem, D. Labiod, S. Château-Joubert et al., "Vandetanib as a potential new treatment for estrogen receptor-negative breast cancers," International Journal of Cancer, vol. 138, no. 10, pp. 2510-2521, 2016. 


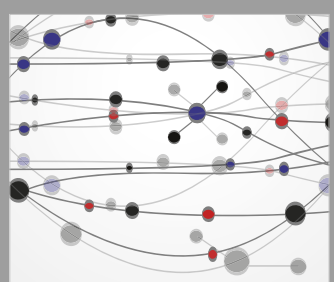

The Scientific World Journal
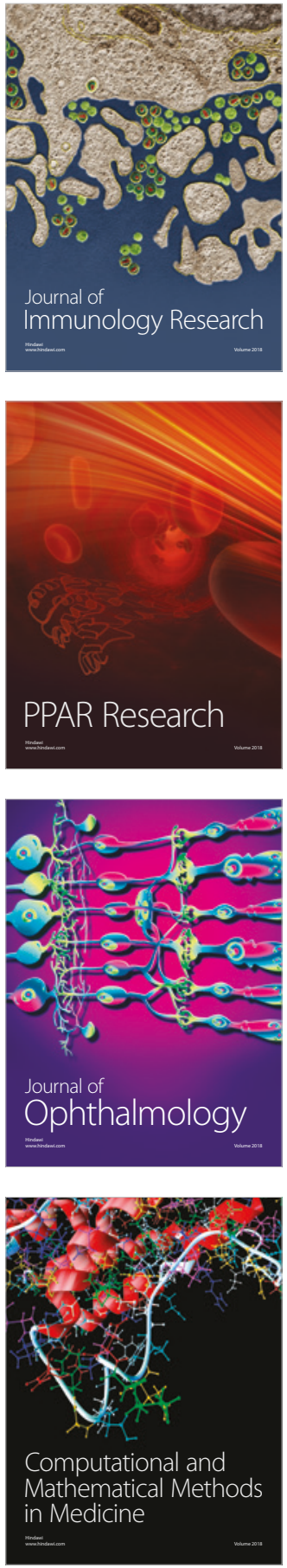

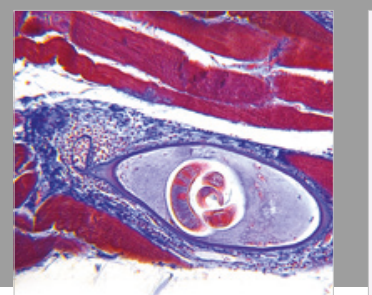

Gastroenterology Research and Practice

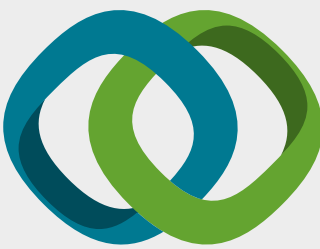

\section{Hindawi}

Submit your manuscripts at

www.hindawi.com
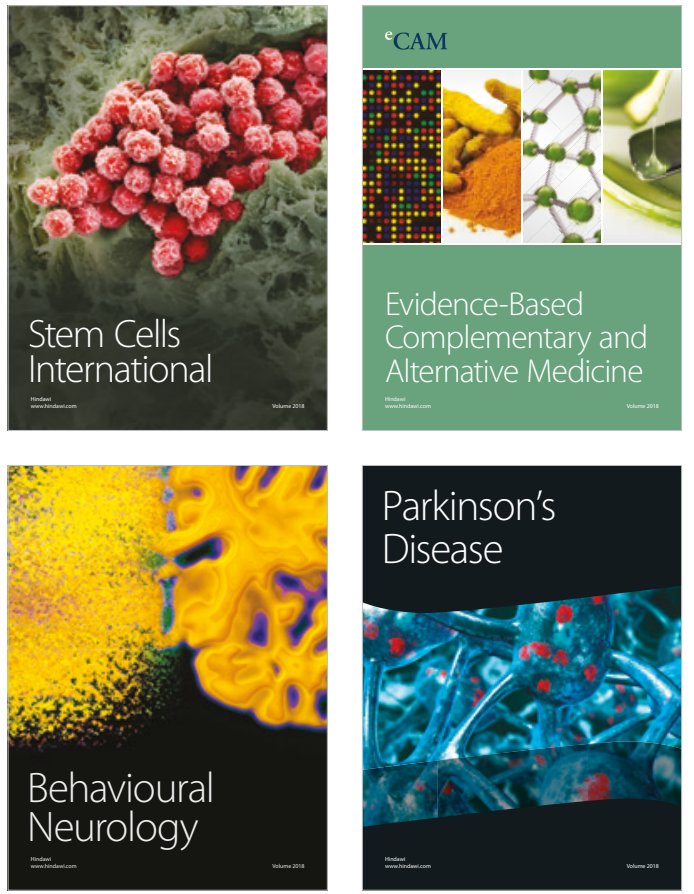

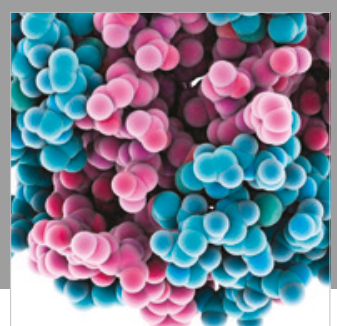

ournal of

Diabetes Research

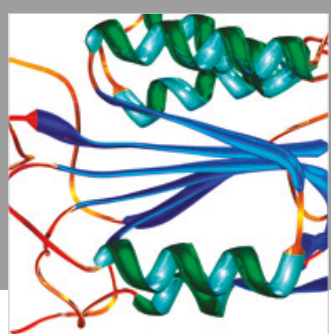

Disease Markers
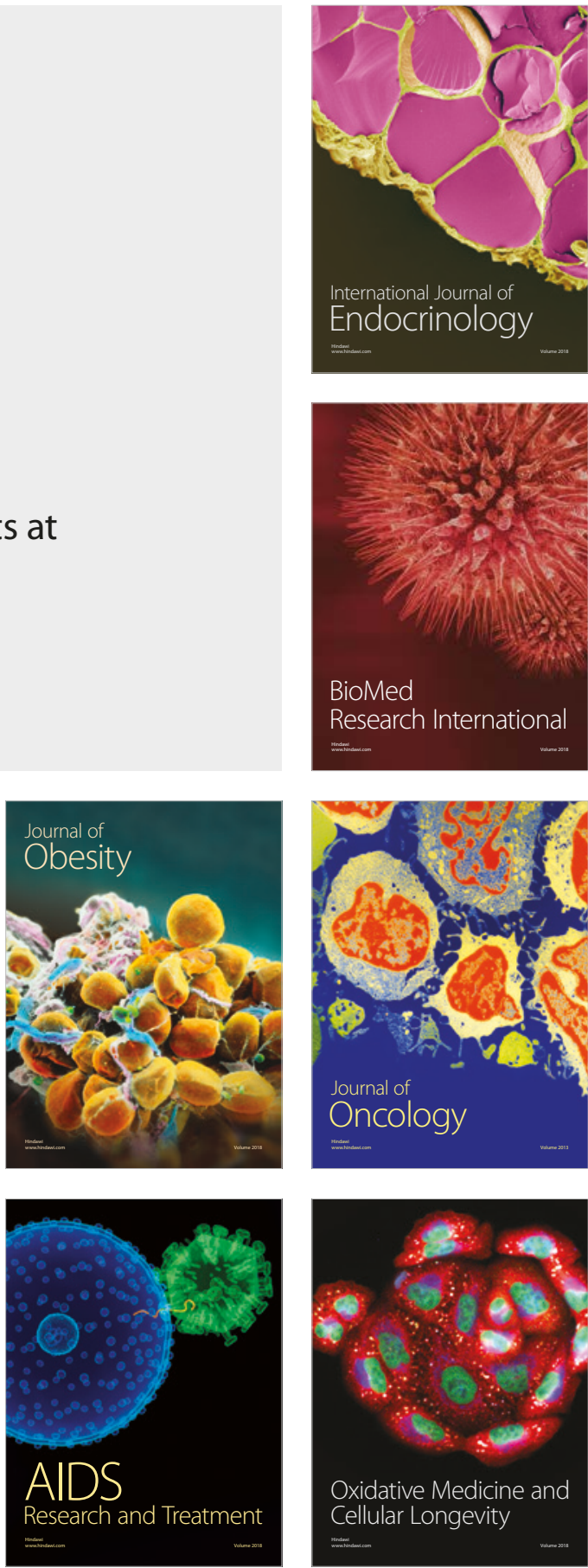